\title{
Solar Tower Experiments for Radiometric Calibration and Validation of Infrared Imaging Assets and Analysis Tools for Entry Aero-Heating Measurements
}

\author{
Scott C. Splinter ${ }^{1}$, Kamran Daryabeigi ${ }^{2}$, and Thomas J. Horvath ${ }^{3}$ \\ NASA Langley Research Center, Hampton, VA 23681 \\ C. David Mercer ${ }^{4}$ \\ Aerospace Computing Inc., Hampton, VA 23681 \\ Cheryl M. Ghanbari ${ }^{5}$ \\ Sandia National Laboratories, Albuquerque, NM 87185 \\ Martin N. Ross ${ }^{6}$ \\ The Aerospace Corporation, Los Angeles, CA 90009 \\ Alan Tietjen ${ }^{7}$ \\ Computer Sciences Corporation, NASA Kennedy Space Center, FL 32899-0001 \\ Richard J. Schwartz ${ }^{8}$ \\ ATK Space Division, Hampton, VA 23681
}

\begin{abstract}
The NASA Engineering and Safety Center sponsored Hypersonic Thermodynamic Infrared Measurements assessment team has a task to perform radiometric calibration and validation of land-based and airborne infrared imaging assets and tools for remote thermographic imaging. The IR assets and tools will be used for thermographic imaging of the Space Shuttle Orbiter during entry aero-heating to provide flight boundary layer transition thermography data that could be utilized for calibration and validation of empirical and theoretical aero-heating tools. A series of tests at the Sandia National Laboratories' National Solar Thermal Test Facility were designed for this task where reflected solar radiation from a field of heliostats was used to heat a 4 foot by 4 foot test panel consisting of LI 900 ceramic tiles located on top of the 200 foot tall Solar Tower. The test panel provided an Orbiter-like entry temperature for the purposes of radiometric calibration and validation. The Solar Tower provided an ideal test bed for this series of radiometric calibration and validation tests because it had the potential to rapidly heat the large test panel to spatially uniform and non-uniform elevated temperatures. Also, the unsheltered-open-air environment of the Solar Tower was conducive to obtaining unobstructed radiometric data by land-based and airborne IR imaging assets. Various thermocouples installed on the test panel and an infrared imager located in close proximity to the test panel were used to obtain surface temperature measurements for evaluation and calibration of the radiometric data from the infrared imaging assets. The overall test environment, test article, test approach, and typical test results are discussed.
\end{abstract}

${ }^{1}$ Aerospace Engineer, Structural Mechanics and Concepts Branch, AIAA Member

${ }^{2}$ Aerospace Engineer, Structural Mechanics and Concepts Branch, AIAA Senior Member

${ }^{3}$ Aerospace Engineer, Aerothermodynamics Branch, AIAA Associate Fellow

${ }^{4}$ Senior Programmer/Analyst, Support to Structural Mechanics and Concepts Branch

${ }^{5}$ Test Engineer, National Solar Thermal Test Facility

${ }^{6}$ Senior Research Staff Scientist, Space Launch Projects

${ }^{7}$ Senior Research Scientist, Innovative Sciences and Technology Experimentation Facility, AIAA Member

${ }^{8}$ Senior Research Scientist, Support to Advanced Sensing and Optical Measurements Branch

This material is declared a work of the U.S. Government and is not subject to copyright protection in the United States. 


\section{Acronyms}

$\begin{array}{ll}\text { BCS } & \text { Beam Characterization System } \\ \text { BLT } & \text { Boundary Layer Transition } \\ \text { CEV } & \text { Crew Exploration Vehicle } \\ \text { EMAF } & \text { Explosives Machining and Assembly Facility } \\ \text { FAA } & \text { Federal Aviation Administration } \\ \text { GPS } & \text { Global Positioning System } \\ \text { HYTHIRM } & \text { Hypersonic Thermodynamic Infrared Measurements } \\ \text { IR } & \text { Infrared } \\ \text { KAFB } & \text { Kirtland Air Force Base } \\ \text { LWIR } & \text { Long-Wave Infrared } \\ \text { MARS } & \text { Mobile Aerospace Reconnaissance System } \\ \text { MATRIS } & \text { Mobile Aerial Tracking and Imaging System } \\ \text { MDT } & \text { Mountain Daylight Time } \\ \text { MWIR } & \text { Mid-Wave Infrared } \\ \text { NESC } & \text { NASA Engineering and Safety Center } \\ \text { NIR } & \text { Near Infrared } \\ \text { NSTTF } & \text { National Solar Thermal Test Facility } \\ \text { RCG } & \text { Reaction Cured Glass } \\ \text { RMS } & \text { Root Mean Square } \\ \text { RTF } & \text { Return-to-Flight } \\ \text { RTV } & \text { Room Temperature Vulcanizing } \\ \text { RVR } & \text { Robotics Vehicle Range } \\ \text { SIP } & \text { Strain Isolation Pad } \\ \text { SSP } & \text { Space Shuttle Program } \\ \text { STS } & \text { Space Transportation System } \\ \text { SWIR } & \text { Short-Wave Infrared } \\ \text { TPS } & \text { Thermal Protection System } \\ \text { ViDI } & \text { Virtual Diagnostics Interface } \\ \text { WAVE } & \text { WB-57 Ascent Video Experiment } \\ & \\ & \end{array}$

\section{Introduction}

$\mathrm{U}$ NDERSTANDING the technical motivation to obtain surface temperatures of hypersonic vehicles in flight is critical to comprehending recent attempts to demonstrate a global flight thermography capability on the Orbiter. In general, heating augmentations and temperature increases resulting from boundary layer transition to turbulence during hypersonic flight through the atmosphere of Earth (or the atmosphere's of other planets - like Mars) impose critical constraints on the design of vehicle thermal protection systems (TPS). The onset of laminarto-turbulent transition and subsequent fully turbulent surface heating determine TPS material selection, placement, and thickness. In terms of vehicle performance, boundary layer transition (BLT) can influence vehicle aerodynamics (i.e., increased drag), landing (or impact) accuracy of autonomously guided spacecraft or delivery systems, and scramjet propulsion system performance. The development of numerical tools for the reliable and rapid prediction of BLT on complex vehicle shapes, however, continues to be hindered by the inability to accurately model the complex physics associated with the transition process. During STS-114's Return-to-Flight (RTF) mission, these uncertainties led to a management decision to conduct an unprecedented spacewalk to remove two protruding gap fillers. If the frequency of inherently risky on-orbit repair operations are to be lowered in the future, uncertainties in predicting early (high Mach number) BLT need to be reduced. Looking towards the future, the present heatshield TPS design philosophy of the Crew Exploration Vehicle (CEV) assumes fully turbulent flow in flight at all times. Under this assumption, uncertainties in predicted surface temperature from numerical turbulence models are of more concern. Collectively, uncertainties in both transition onset and turbulent heating can impose unnecessarily large TPS margins that translate to reduced payload capability and degraded mission performance.

Relative to discrete onboard surface instrumentation, the passive nature of infrared (IR) thermography makes it a very powerful tool to observe surface flow phenomena from a global perspective. Any flow phenomena that create measurable surface temperature changes such as shock wave interactions, flow separation, and BLT could be visualized. Quantitatively, if surface temperatures associated with a hypersonic laminar and fully turbulent boundary layer flow can be inferred from calibrated imagery they could be used to verify numerical predictive 
methods and associated turbulence models with flight data. While most aerospace applications of IR thermography have been limited to wind tunnel testing, the Space Shuttle Program (SSP) has attempted to utilize this measurement technique several times over the past 25 years to obtain flight data ${ }^{1-7}$. The most recent imagery during a Space Shuttle Orbiter entry ${ }^{8}$ was motivated by the desire to reduce uncertainties associated with an empirical transition prediction strategy. This empirical methodology is presently derived from ground-based measurements that are extrapolated to flight using representative (and limited) flight data. During the RTF BLT predictive tool development phase, it was recognized that the level of conservatism imposed by these extrapolation uncertainties could be more clearly established and/or reduced with quality data from a controlled roughness flight experiment. Advocacy from the technical community has resulted in SSP support of a hypersonic boundary layer flight test. In the planned test, an isolated protuberance located on the Orbiter wing will be used to induce BLT and turbulence at hypersonic non-equilibrium conditions 9 . Global temperature IR images with adequate spatial resolution and dynamic range could non-intrusively complement the discrete thermocouple data by providing spatially continuous surface temperature at targeted Mach number(s). Recognizing the tremendous opportunity of this Orbiter BLT flight test which will not be available upon retirement of the Space Shuttle in 2010, the NASA Engineering and Safety Center (NESC) has sponsored the development of a team of technical experts to assess existing imaging capability within the U.S. and to develop and validate a mission planning tool set. The overall goal of the assessment team is to demonstrate the viability of obtaining global temperature measurements of hypersonic flight vehicles using the nation's existing suite of applicable imaging assets. The near term target of opportunity is (but not limited to) the Orbiter BLT flight experiment currently planned for 2009.

The present paper provides an overview of the NESC Hypersonic THermodynamic InfraRed Measurement (HYTHIRM) assessment team's series of tests at the Sandia National Laboratories' National Solar Thermal Test Facility (NSTTF) to perform radiometric calibration and validation of land-based and airborne IR imaging assets and tools for remote thermographic imaging. These IR assets and tools could subsequently be used for thermographic imaging of the Orbiter during entry aero-heating to provide flight BLT thermography data that could be utilized for calibration and validation of empirical and theoretical aero-heating tools. The NSTTF, the infrared imaging assets and staging sites, testing logistics, test article and stand, test conditions, and typical test results will be discussed. This paper is, and is intended as, the third part of a series of four papers on the viability of quantitative spatially resolved flight thermography. The first paper, Ref. 10, is an overview of the NESC HYTHIRM assessment team and the integrated effort that was involved with identification and cataloging of relevant optical imaging assets and the development, maturation, and validation of simulation and modeling tools for assessment and mission planning purposes. The second paper, Ref. 11, provides the results of a system trade study using the simulation modeling tools ${ }^{12}$ developed during the initial HYTHIRM effort. Finally, the fourth paper, Ref. 13, provides an update on the Orbiter flight experiment and the synergy with a HYTHIRM ancillary global data collection.

\section{Test Environment}

\section{A. National Solar Thermal Test Facility}

This series of tests were conducted at the Sandia National Laboratories' National Solar Thermal Test Facility (NSTTF) in Albuquerque, New Mexico. The NSTTF consists primarily of a 200 foot tall concrete tower known as the Solar Tower shown in Fig. 1, a field of 212 mirrored solar collectors known as heliostats and a heliostat control tower shown in Fig. 2, and several other support buildings and structures. The primary, or west, test stand which supported the test article for this series of tests was located on the top level of the Solar Tower in an unshelteredopen-air environment as shown in Figs. 3 and 4. Also shown adjacent, or east, of the primary test stand in Figs. 3 and 4 is the calibration test stand which was used to determine solar flux heating levels and spatial aim-points for the heliostat solar beams prior to testing. Behind, or to the south, of the primary test stand was an insulated shed used for observation of the tests and storing the test article overnight shown in Fig. 3. The test stands were maintained in a horizontal position for test article installation and instrumentation hookup. During testing, the calibration and primary test stands were then rotated 90 degrees from horizontal into the vertical test position facing the heliostat field as shown in Figs. 3 and 4. The heliostat field was brought online with the solar beams from the heliostats parked in a safe region just to the east and above the Solar Tower top level known as the standby far-east position, and were then brought onto the calibration and primary test stands in groups as needed to generate the required heating and temperature conditions. The test article for this series of tests consisted of an 8 by 8 array of LI 900 ceramic tiles, same as the tiles used on the windward surface of the Orbiter, which created a 4 foot by 4 foot tile array test panel. The standard test article size for the NSTTF is either 1 foot by 1 foot or 2 foot by 2 foot. Therefore, conducting tests and maintaining uniform heating on the 4 foot by 4 foot test panel was an unverified 
capability. The NSTTF can produce heat fluxes as high as $220 \mathrm{Btu} / \mathrm{ft}^{2}-\mathrm{s}\left(250 \mathrm{~W} / \mathrm{cm}^{2}\right)$, and is typically used for the testing of ablative thermal protection systems ${ }^{14,15}$. The Solar Tower provided an ideal test bed for this series of radiometric calibration and validation tests because it had the potential to rapidly heat the large test panel to spatially uniform and non-uniform elevated temperatures. Also, the unsheltered-open-air environment of the Solar Tower was conducive to obtaining unobstructed radiometric data by land-based and airborne IR imaging assets.

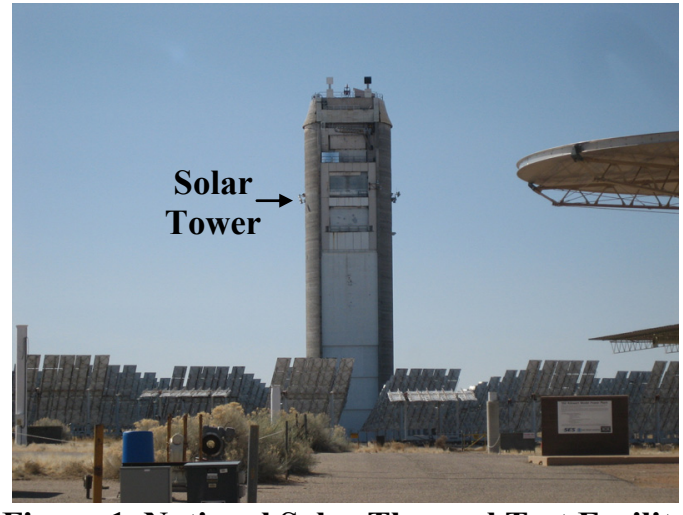

Figure 1. National Solar Thermal Test Facility

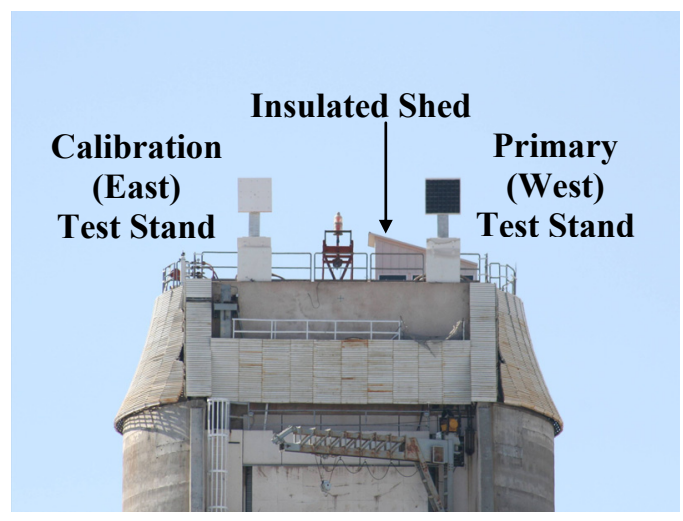

Figure 3. Solar Tower top level, front

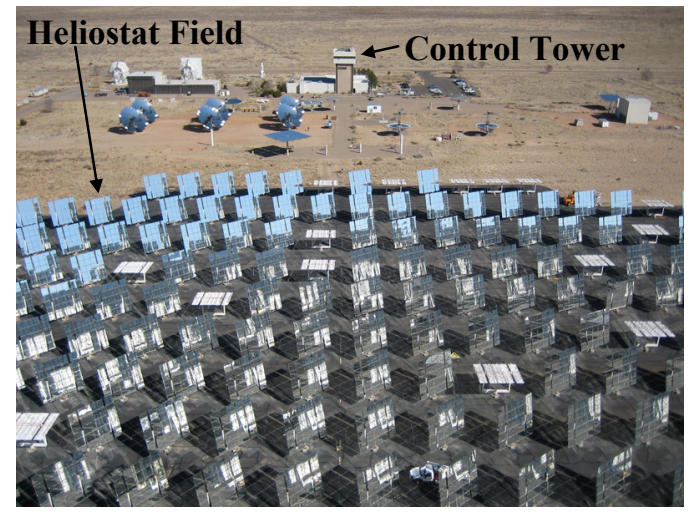

Figure 2. National Solar Thermal Test Facility

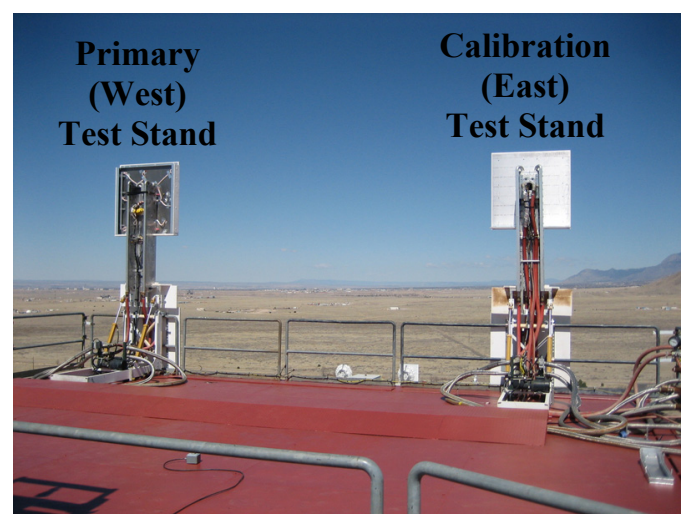

Figure 4. Solar Tower top level, back

\section{B. Infrared Imaging Assets}

Three land-based IR imaging assets were staged at three different sites on four consecutive days with an airborne IR asset participating on two non-consecutive days for a total of five days of testing. The three land-based IR imaging assets consisted of the Mobile Aerospace Reconnaissance System (MARS) shown in Fig. 5 which was operated by the Clay Center Observatory for the Dexter Southfield Schools, the WB-57 Ascent Video Experiment (WAVE) optical bench system shown in Fig. 6 which was removed from one of the WB-57 aircraft and operated by the Southern Research Institute for the WB-57F Program at NASA Johnson Space Center, and the Mobile Aerial TRacking and Imaging System ${ }^{16}$ (MATRIS) shown in Fig. 7 operated by the NASA Dryden Flight Research Center. The airborne IR asset was the Cast Glance P-3 Orion aircraft shown in Fig. 8 which was operated by NAVAIR for the US Navy. The MARS system used near infrared (NIR) and short-wave infrared (SWIR) imagers, the WAVE system used a NIR imager, the MATRIS system used a mid-wave infrared (MWIR) imager, and the Cast Glance P-3 Orion aircraft used NIR and MWIR imagers for imaging the tile array test panel atop the Solar Tower. Several landbased sites were selected as potential staging locations for the IR imaging assets, however only three sites were utilized in the time allotted for performing this series of tests. In order from the farthest to the closest land-based staging site from the Solar Tower, site 1 hosted the MARS, WAVE, and MATRIS systems, site 2 hosted the MARS and WAVE systems with the MATRIS system remaining at site 1, and site 3 hosted the MARS system. The focal lengths of the MATRIS and WAVE imaging systems did not allow for movement to a site closer to the Solar Tower than these respective sites. The Cast Glance aircraft participated on the same day the MARS and WAVE systems were at site 2 and on a day by itself without staged land-based IR assets. All IR assets were able to successfully image the tile array test panel at various test conditions from their respective sites. 


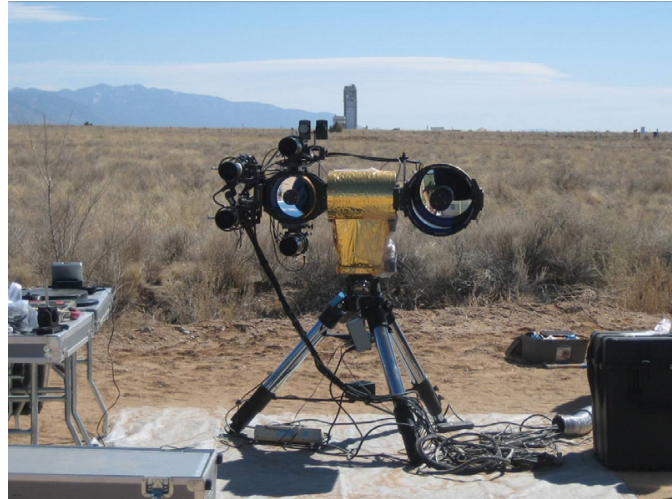

Figure 5. MARS system

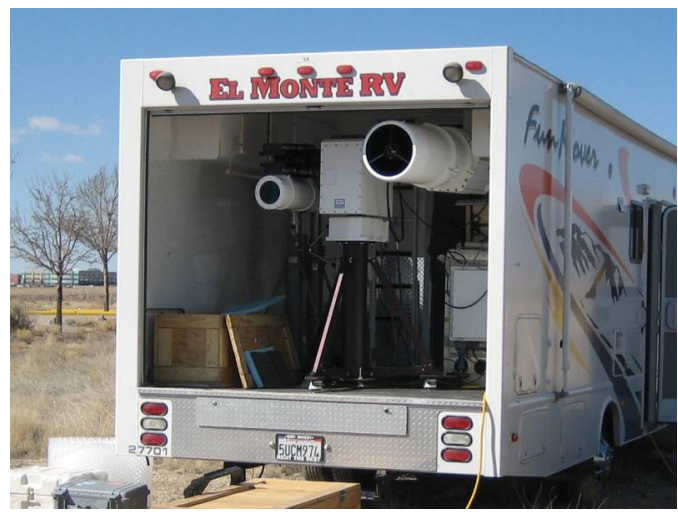

Figure 7. MATRIS system

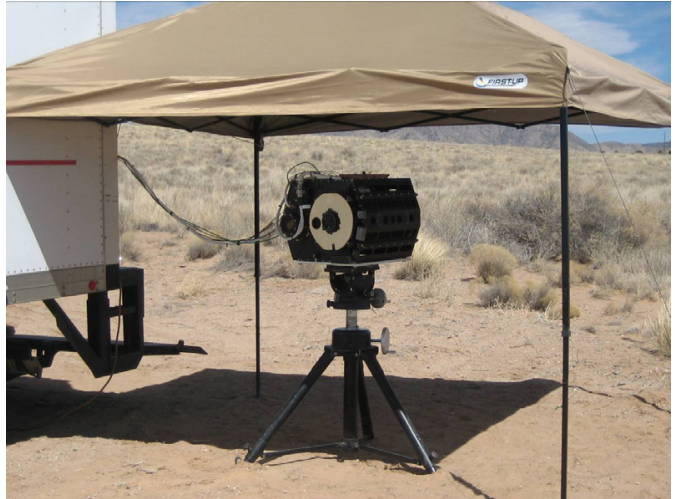

Figure 6. WAVE optical bench system

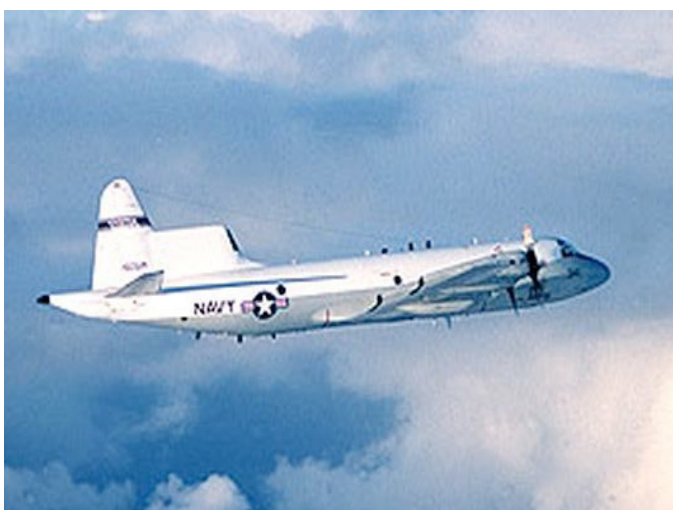

Figure 8. Cast Glance P-3 Orion aircraft

\section{Staging Sites}

The land-based staging sites were chosen based on distance from the Solar Tower, vehicle and equipment accessibility via paved and gravel roads, available flat and open areas for staging equipment, availability of support buildings (i.e. restrooms, conference room, storage area, etc.), and most importantly for an unobstructed view of the Solar Tower. Preliminary selection of land-based sites was performed using Google Earth ${ }^{\text {TM17 }}$, Google Maps ${ }^{\text {TM18 }}$, and the Virtual Diagnostics Interface ${ }^{19}$ (ViDI) software packages to determine a candidate site's distance from the Solar Tower, its ease of accessibility and staging, the locations of support buildings, and to evaluate any visual obstructions and the acquired image size for each asset based on its field of view, respectively. Final down-selection of candidate land-based sites was determined through site visits. Figure 9 shows the locations of the IR imaging assets' land-based and airborne staging sites as viewed from the top level of the Solar Tower. All three land-based staging sites are described below along with the airborne asset's staging proximity to the Solar Tower.

The Sandia National Laboratories' Robotics Vehicle Range (RVR) was chosen as Site 1 and is shown in Fig. 10. The RVR site was located approximately 5.3 miles from the Solar Tower, and had an unobstructed view of the Solar Tower as shown in Fig. 11. The Sandia National Laboratories' Explosives Machining and Assembly Facility (EMAF) was chosen as Site 2 and is shown in Fig. 12. The EMAF site was located approximately 1.4 miles from the Solar Tower, and the unobstructed view of the Solar Tower from this site is shown in Fig. 13. The Sandia National Laboratories' NSTTF was chosen as Site 3 and is shown in Fig. 14. The site at the NSTTF was located approximately 0.3 miles from the Solar Tower, and had an unobstructed view of the Solar Tower as shown in Fig. 15. The land-based IR assets took approximately three to four hours each day to setup and stow their equipment.

Other land-based staging sites that were considered but never utilized were the parking lot of the Sandia Peak Ski and Tramway Employees' Office Building and the observation deck at the top of the Sandia Peak Tramway. These sites would have provided fair views of the Solar Tower from approximately 18 miles away at two very different elevations. Both sites were reasonably accessible for the land-based IR assets and were surrounded by several support buildings. Use of the parking lot of the Sandia Peak Ski and Tramway Employees' Office Building was ruled out because of concerns with excessive thermal radiation and turbulence coming from the ground and 
buildings in the optical path to the Solar Tower. Use of the observation deck on the Sandia Peak Tramway was eventually ruled out because of snow accumulation on the peak during the test period.

The Cast Glance P-3 Orion aircraft shown in Fig. 8 also participated in this series of tests as shown in Fig. 16. This airborne IR asset flew six test support position profiles with proximities of 30,25, 20, 15, 10, and 5 nautical miles from the Solar Tower on two separate test days. A visible spectrum view of the Solar Tower from the airborne IR asset at 15 nautical miles is shown in Fig. 17. The airborne IR asset had an approximate 2 hour transit flight departing from and returning to its home airbase and had to obtain Federal Aviation Administration (FAA) airspace clearances each test day. Each test day with the airborne IR asset was driven by a fixed schedule with tests being performed every 20 minutes from which the airborne IR asset pre-determined its test support profiles.

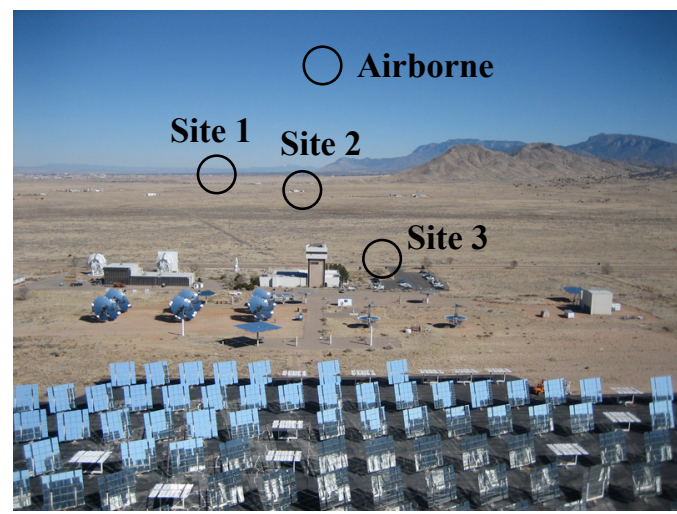

Figure 9. View of NSTTF and staging sites from Solar Tower top level

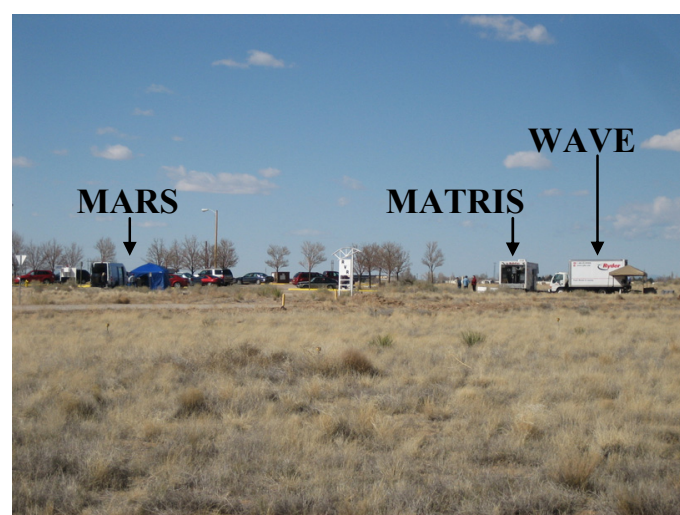

Figure 10. Site $1(R V R)$ staging area

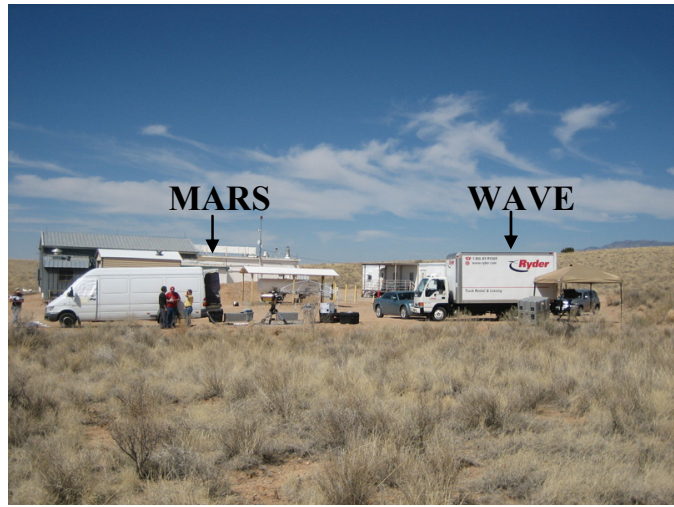

Figure 12. Site 2 (EMAF) staging area

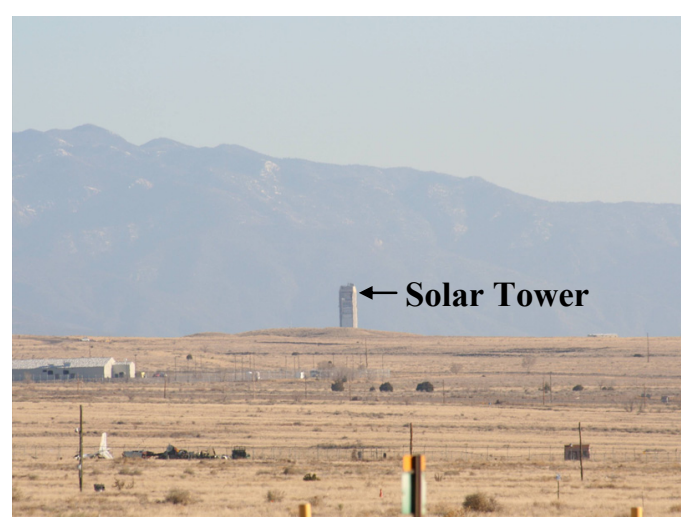

Figure 11. View of Solar Tower from Site 1 (300mm Magnification)

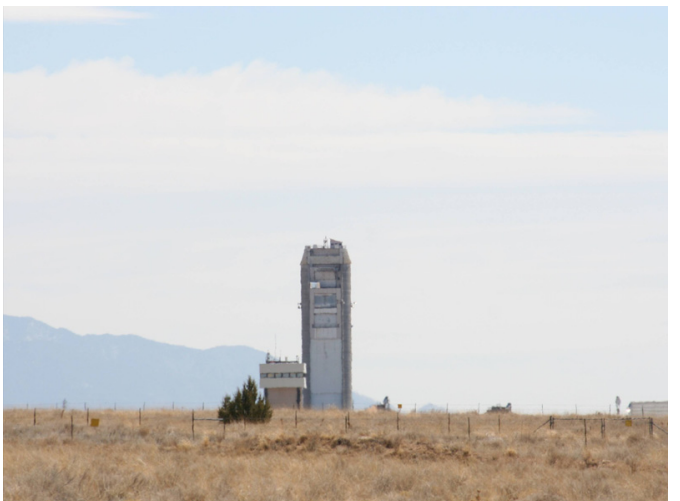

Figure 13. View of Solar Tower from Site 2 (70mm Magnification) 


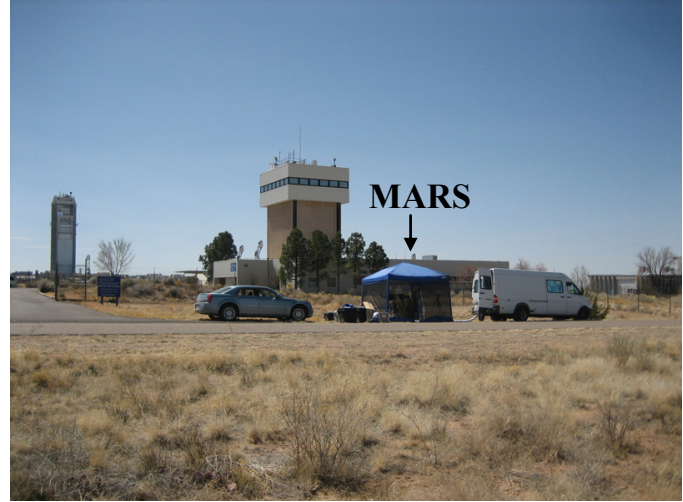

Figure 14. Site 3 (NSTTF) staging area

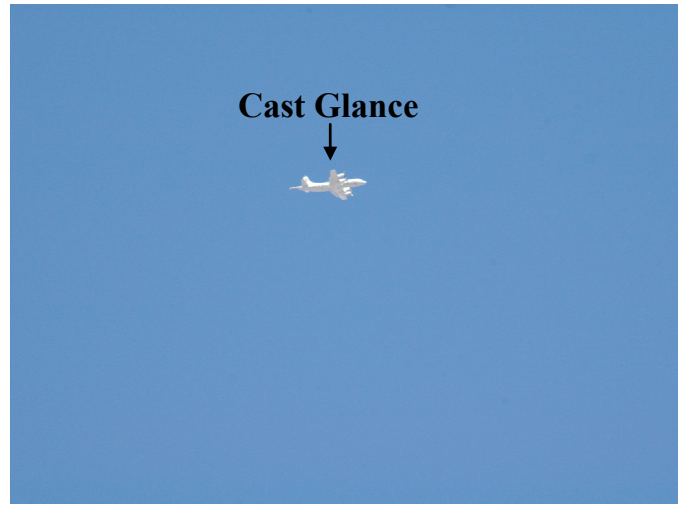

Figure 16. Airborne staging

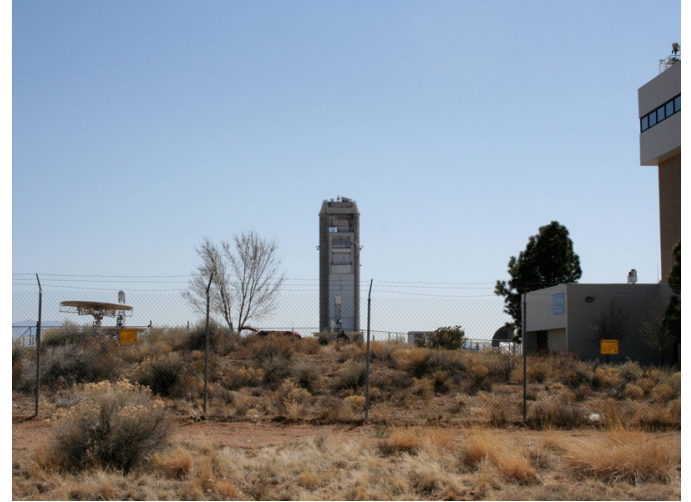

Figure 15. View of Solar Tower from Site 3 (35mm Magnification)

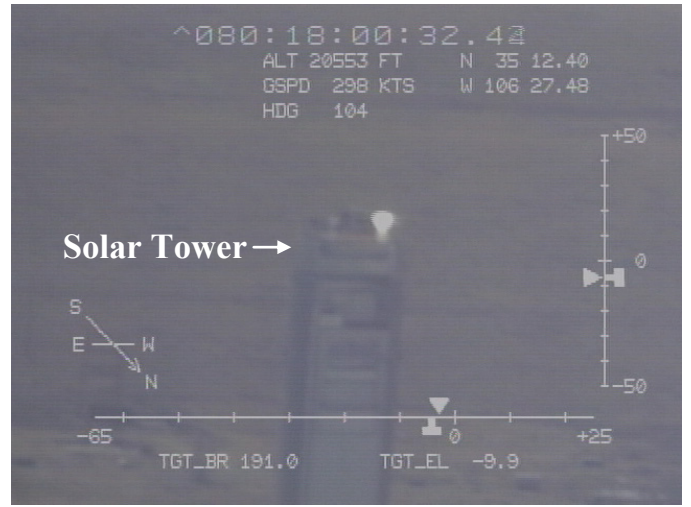

Figure 17. View of Solar Tower from 15 nmi (Unknown Magnification)

\section{Testing Logistics}

The NSTTF handheld radios were used as the primary form of communications between the NSTTF and the land-based staging sites due to broadcasting restrictions from Sandia property. Cell phones were selected as the backup form of communications with cell phone antenna boosters utilized for improved reception levels at the NSTTF. The primary form of communication with the airborne IR asset for this series of tests was via the aircraft's satellite phone to a land-line phone in the NSTTF control tower. Communications between the airborne IR asset and the NSTTF control tower were aircraft initiated.

Handheld global positioning system (GPS) units were used to synchronize time to within a second on the various data acquisition systems used by the IR assets and the NSTTF. Two forms of time synchronization were employed during this series of tests. The first was flexible-time synchronization where tests were executed at a group determined GPS time based on when the IR assets and NSTTF Test Engineer were ready for each test, and the second was fixed time synchronization where the tests were started at GPS 11:00 AM MDT and executed every 20 minutes after that time regardless of the test conditions achieved (i.e. clouds obstructing the heliostats limiting the target solar flux level) or the land-based IR assets being ready. The fixed-time synchronization was driven by the airborne IR asset. Since the NSTTF relies on the sun for testing, the test window for each day was between 11:00 AM and 3:00 PM MDT (a two hour period on either side of solar noon) so that the sun was at the optimum angle to provide maximum and consistent solar flux levels.

Power source options at each of the land-based staging sites for this series of tests consisted primarily of portable-gas-powered and vehicle-powered generators, with building power supplied by extension cords as a backup but never utilized. The portable-gas-powered and vehicle-powered generators were chosen as the primary power source due to their flexibility and reduced reliance on staging area host personnel. 


\section{Test Article}

\section{A. Tile Array Test Panel}

The test article for this series of tests consisted of an 8 by 8 array of 6 inch by 6 inch by 2 inch thick reaction cured glass (RCG) coated LI 900 ceramic tiles, same as the tiles used on the windward surface of the Orbiter, which created a 4 foot by 4 foot tile array test panel. The test panel provided an Orbiter-like entry temperature for the purposes of radiometric calibration and validation. Pictures and schematics of the tile array test panel are shown in Figs. 18 through 21. Figures 18 and 19 are pictures of the front and back of the test panel as fabricated without side insulation boards. Figures 20 and 21 are schematics of the front and back of the test panel describing the important features and the locations of the instrumented tiles. Figure 21 also depicts the "footprint" of the NSTTF test stand and the mounting hooks, brackets, and straps that were used to secure the test panel to the stand.

The tile array test panel was composed of 12 instrumented and 52 un-instrumented RCG coated LI 900 ceramic tiles mounted to a 0.375 inches thick aluminum panel using Orbiter equivalent room temperature vulcanizing (RTV) adhesive and strain isolation pads (SIP), with the gaps in-between each of the tiles filled by non-Orbiter equivalent 0.050 inches thick alumina paper insulation. The installation process for the LI 900 ceramic tiles on the tile array test panel was performed in a similar manner as the installation process for these tiles on the Orbiter. The 12 instrumented and 52 un-instrumented LI 900 ceramic tiles can be distinguished in Fig. 18 by their lack or inclusion of white Orbiter tile serial numbering, respectively. The 12 instrumented LI 900 tiles were fabricated by NASA Kennedy Space Center with Type-R thermocouples positioned at the tile/RCG coating interface, using the standard installation method for instrumented tiles on the Orbiter. The instrumented tiles were arranged on the tile array test panel in such a manner as to efficiently capture any temperature gradients across the test panel with the fewest number of instrumented tiles possible. Holes were drilled in the 0.375 inches thick aluminum panel to accommodate the lead wires from the instrumented tiles which were wrapped in $\mathrm{Nextel}^{\mathrm{TM}}$ ceramic threaded sleeves for electrical isolation and protection. All instrumented tile lead wires were then secured in place with aluminum tape, and routed towards the center of the tile array test panel where they were combined into one common pigtail as shown in Fig. 19. Fourteen Type-K thermocouples were also installed on the tile array test panel and routed to the same common pigtail. Twelve of the Type-K thermocouples were secured to the back surface of the aluminum panel behind the centers of the instrumented tiles to monitor the aluminum panel temperature, and the remaining two were inserted near the base of the numbers 1 and 7 instrumented tiles shown in Fig. 20 to monitor the tile/SIP RTV bond-line temperature. An additional Type-K thermocouple was also used to measure the junction temperature at the interface between the Type-R thermocouple lead wires and the copper lead wires of the NSTTF data acquisition system. Finally, several brackets, hooks, and square aluminum tubes were added to the back surface of the aluminum panel for mounting it to the NSTTF test stand, mounting the side insulation boards to the panel, and for carrying and standing up the tile array test panel when it was not being tested as shown in Figs. 19 and 21.

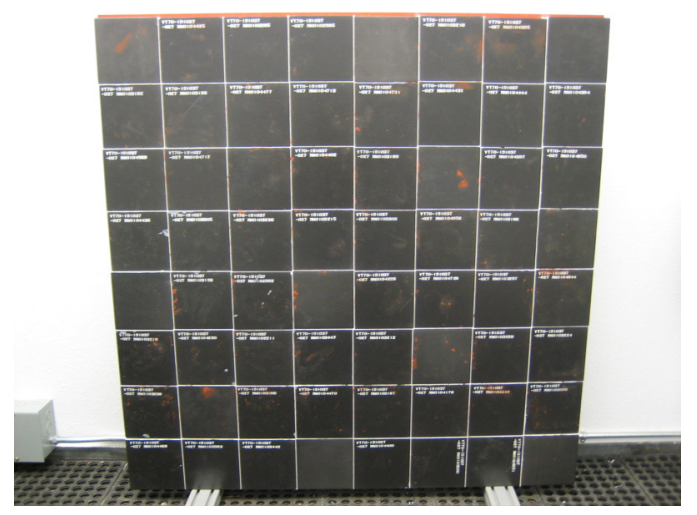

Figure 18. Tile array test panel, front

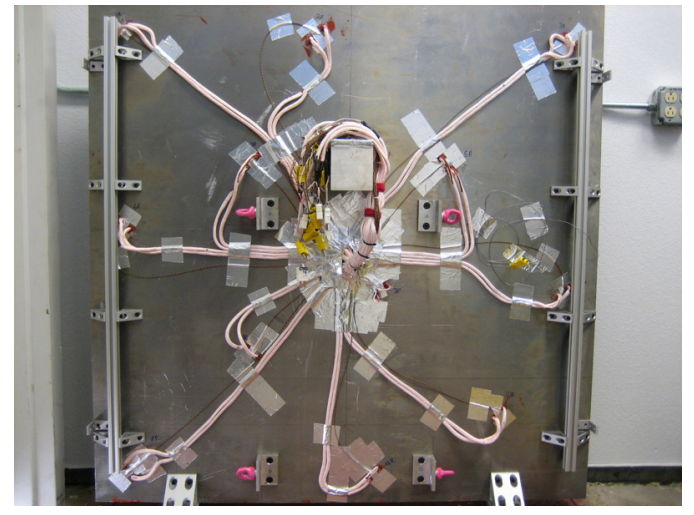

Figure 19. Tile array test panel, back 


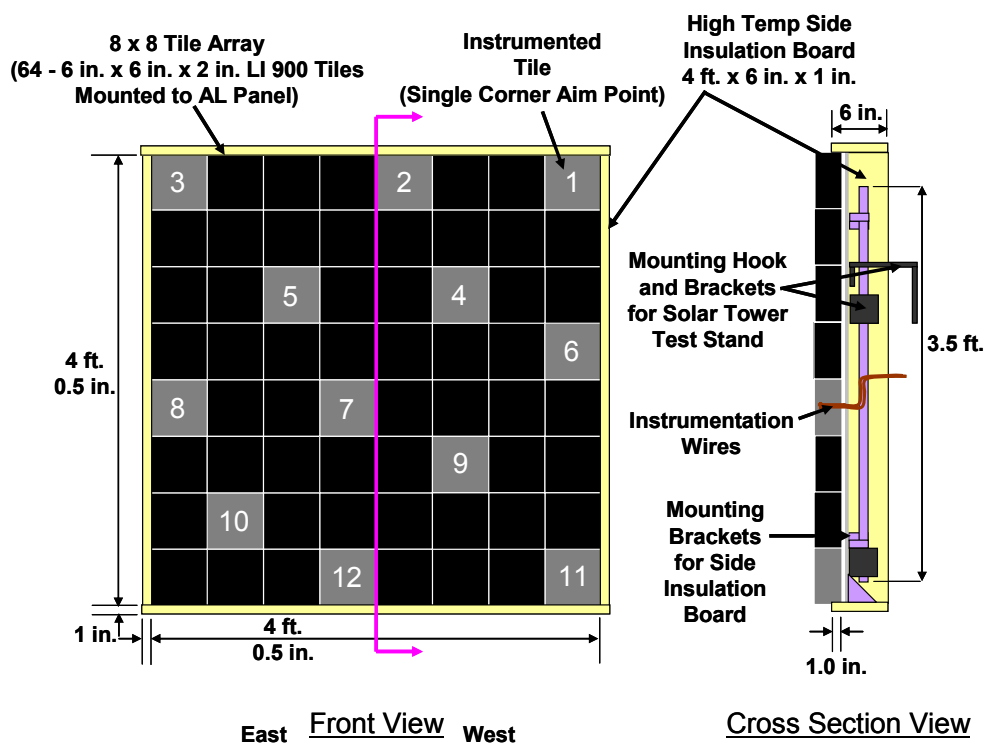

Figure 20. Tile array test panel schematic, front

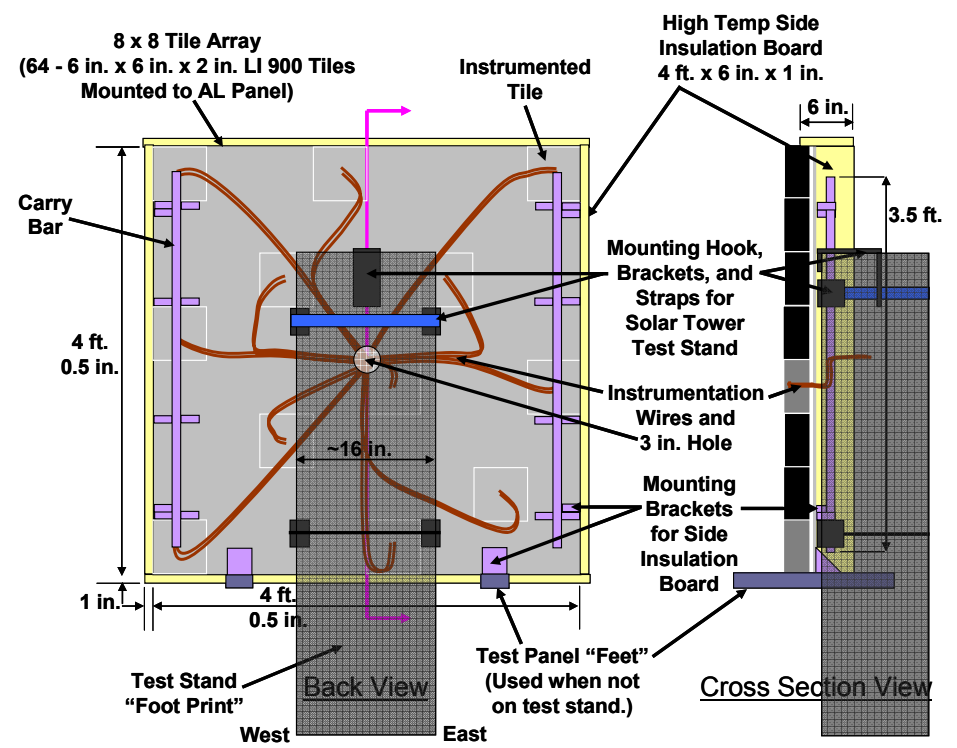

Figure 21. Tile array test panel schematic, back

\section{B. NSTTF Test Stand}

A picture of the NSTTF primary, or west, test stand to which the tile array test panel was mounted for this series of tests is shown in Fig. 22. The NSTTF test stands are a series of 2 inch thick by 6 inch wide by 5.5 feet long rectangular aluminum tubes for cooling water that form an upside-down U-shaped channel which shelters hoses and instrumentation connections from the heating of the heliostat solar beams. The test stand started out in the horizontal position shown in Fig. 22, with the tile array test panel held over it by four people with a fifth person that fed the common thermocouple pigtail through a 3 inch diameter hole in its center. Once the common thermocouple pigtail was fed through the test stand, the test panel was lowered down into position so that the mounting hook on the back of the panel hung securely on the end of the test stand. A nylon cargo strap and thin gage steel wire were then connected to the mounting brackets on the test panel and tightened around the back of the test stand to secure the test panel in place as shown previously in Fig. 21. The thin gage steel wire was used instead of another nylon cargo strap near the bottom of the test panel due to the possibility of excessive heating in this area by solar beams 
behind the test panel. Next, the high temperature side insulation boards were added around the test panel to shade the instrumentation lead wires and carrying hardware from stray solar beams, with any gaps between the side insulation boards and the LI 900 tiles on the front surface of the test panel filled with strips of the alumina paper insulation, thus completing the assembly and mounting of the tile array test panel as shown in Fig. 23. Also shown in Fig. 23 is the location of the Kendall Radiometer for measuring the solar flux level on the primary test stand. This radiometer was located below and partially covered by the test panel making its solar flux measurements inaccurate. However it still served as an indication of when the solar beams illuminated the test panel. The Kendall radiometer located in the center of the calibration, or east, test stand was used to determine the solar flux levels for each test. The primary test stand was then moved via a hydraulic motor into a suitable position to connect the thermocouples on the test panel to the NSTTF data acquisition system as shown in Fig. 24 . Once all the thermocouples were connected, the test stand was further moved into the 90 degree vertical test position as shown in Fig. 25, with the test angle verified by an inclinometer. Mounting, assembly, and positioning of the tile array test panel and test stand was performed in approximately 15 minutes by a total of five people. Figures 26 and 27 show the back and front, respectively, of the tile array test panel and NSTTF primary test stand illuminated by the solar beams during a test. Note the reflection of the solar beams off the sides of the NSTTF primary test stand behind the test panel in Fig. 26 where the thin gage steel wire was located. No degradation of this steel wire from the solar beams was noticed during this series of tests.

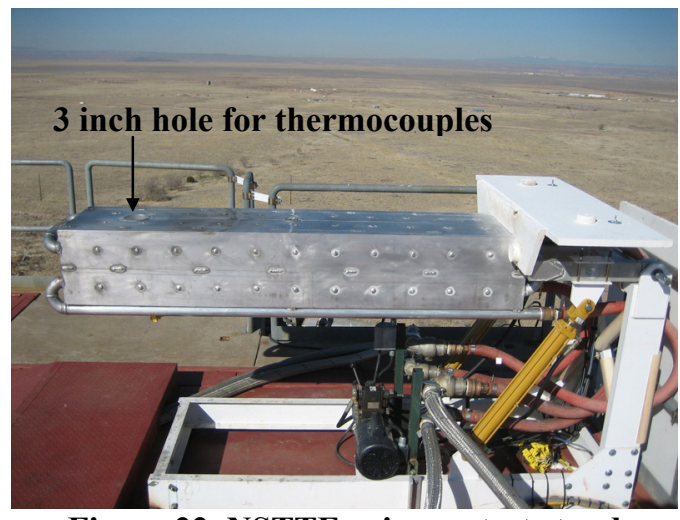

Figure 22. NSTTF primary test stand

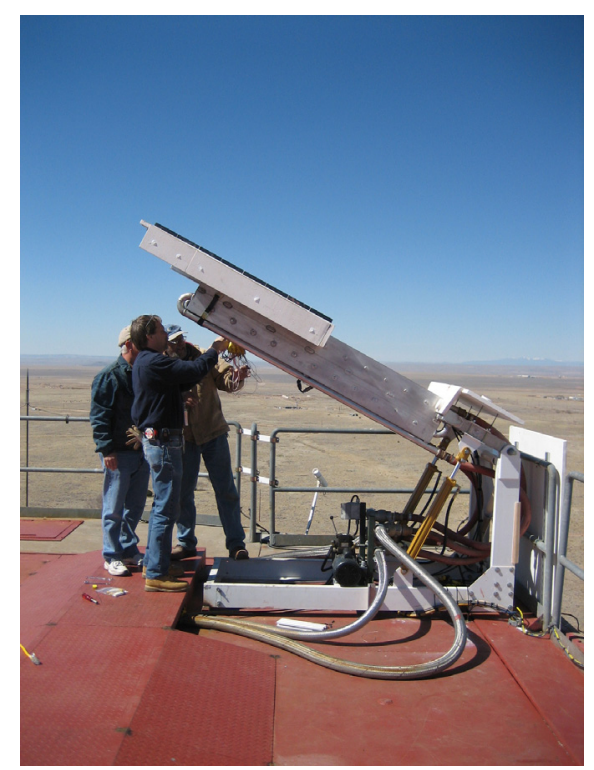

Figure 24. Connecting of thermocouples

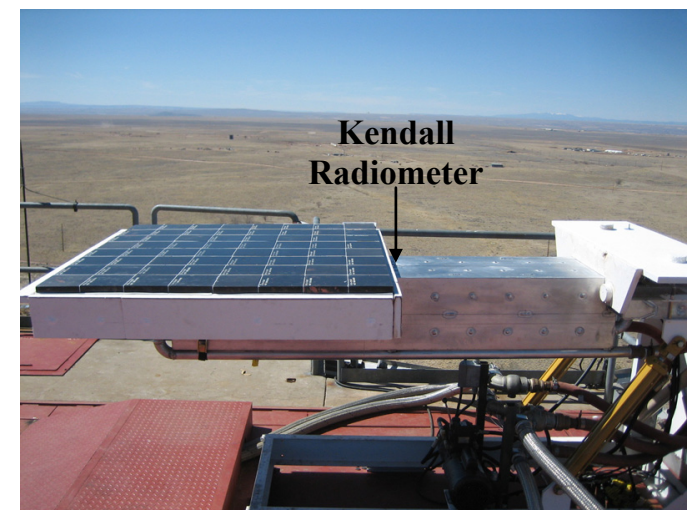

Figure 23. NSTTF primary test stand with tile array test panel mounted

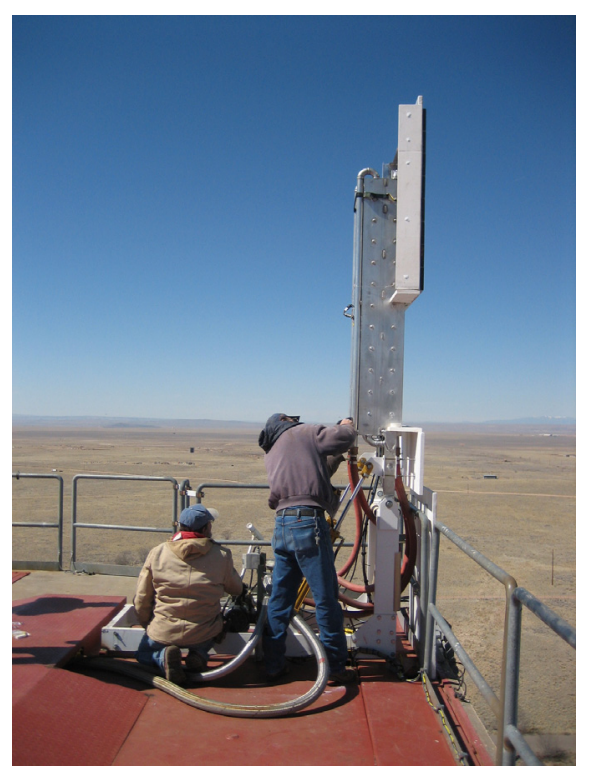

Figure 25. Positioning of tile array test panel and NSTTF primary test stand for testing 


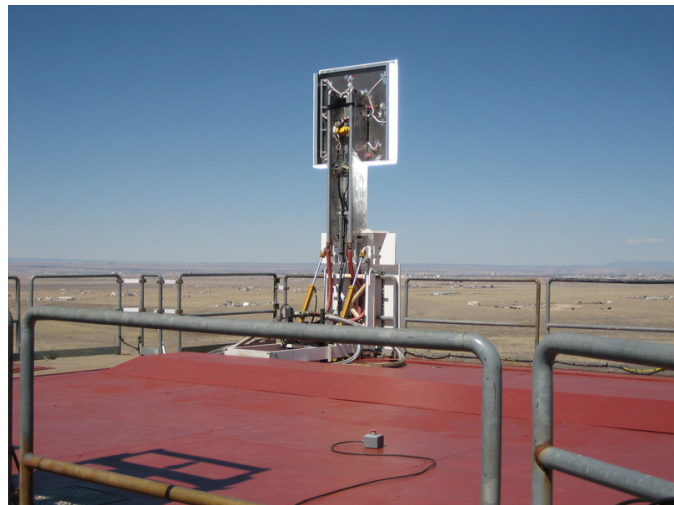

Figure 26. Tile array test panel and NSTTF test stand illuminated by solar beams, back

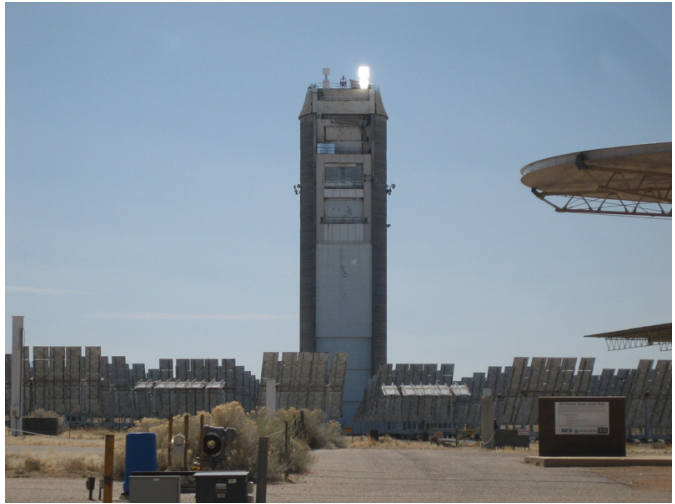

Figure 27. Tile array test panel and NSTTF test stand illuminated by solar beams, front

\section{Test Approach}

\section{A. Test Conditions}

The purpose of this series of tests was to rapidly heat the tile array test panel to spatially uniform and nonuniform elevated temperatures with the solar beams from the heliostats in the unsheltered-open-air environment of the Solar Tower to obtain unobstructed radiometric data (i.e. sensor output digital units, or counts, as functions of temperature from NIR, SWIR, and MWIR images of an Orbiter-like entry temperature) for evaluation and calibration of the land-based and airborne IR imaging assets, and for validation of the total radiance analysis tool. Two types of test conditions were planned: uniform spatial heating of the test panel to various target temperatures as depicted in Fig. 28, and non-uniform spatial heating of the test panel with a large temperature gradient maintained across the diagonal of the test panel $\left(2000^{\circ} \mathrm{F}\right.$ at one corner and $1000^{\circ} \mathrm{F}$ or lower at the opposite corner) as depicted in Fig. 29. The latter was mainly used to determine the intra-frame dynamic range of the IR assets. During the first day of testing, an irregular shaped lobe was observed below the test panel in the IR images for the uniform spatial heating test condition due to unanticipated reflectance of the solar beams off the exposed NSTTF test stand supports. Because of this, a third test condition was added which consisted of non-uniform spatial heating of the test panel with a large temperature gradient maintained from top to bottom on the test panel (target temperature across the top and $1000^{\circ} \mathrm{F}$ or lower across the bottom) as depicted in Fig. 30, to minimize reflectance of the solar beams from the test stand supports.

The spatially uniform and non-uniform heating of the tile array test panel to target temperatures was composed of various combinations of two different heating and cooling rates. The two different heating rates consisted of an instant application of the solar beams to the test panel, termed rapid heating, and a ramped application of the solar beams to the test panel in separate groups spaced over one minute, termed slow heating. Similarly, the two different cooling rates consisted of an instant removal of the solar beams from the test panel, termed rapid cooling, and a ramped removal of the solar beams from the test panel in separate groups spaced over two minutes, termed slow cooling. The target elevated temperature was then dwelled at for approximately two minutes in-between the selected heating and cooling rates, with the resulting temperature profiles shown in Fig. 31.

The test matrix for this series of tests is provided in Table 1 based on the aforementioned test conditions. The series of tests performed on Day 1 consisted of six uniform spatial heating tests (three at $2000^{\circ} \mathrm{F}$, one at $1500^{\circ} \mathrm{F}$, and two at $1000^{\circ} \mathrm{F}$ ) and two non-uniform diagonal spatial heating tests. Day 1 tests were performed with a mix of rapid and slow heating and cooling rates. The series of tests performed on Day 2 consisted of ten non-uniform top-tobottom spatial heating tests (one each at $2000^{\circ} \mathrm{F}$ and $1900^{\circ} \mathrm{F}$, two each at $1700^{\circ} \mathrm{F}$ and $1600^{\circ} \mathrm{F}$, and one each at $1200^{\circ} \mathrm{F}, 1000^{\circ} \mathrm{F}, 800^{\circ} \mathrm{F}$, and $600^{\circ} \mathrm{F}$ ). All tests on Day 2 were performed with rapid heating and cooling rates, except for the $800^{\circ} \mathrm{F}$ test which was performed with slow heating. The series of tests performed on Day 3 consisted of one uniform spatial heating test $\left(2000^{\circ} \mathrm{F}\right)$, two non-uniform diagonal spatial heating tests, and six non-uniform top-tobottom spatial heating tests (four at $2000^{\circ} \mathrm{F}$, one at $1800^{\circ} \mathrm{F}$, and one at $1700^{\circ} \mathrm{F}$ ). All tests on Day 3 were performed with rapid heating and cooling rates. The series of tests performed on Day 4 consisted of one uniform spatial heating test $\left(2000^{\circ} \mathrm{F}\right)$, two non-uniform diagonal spatial heating tests, and four non-uniform top-to-bottom spatial heating tests (one each at $2000^{\circ} \mathrm{F}, 1600^{\circ} \mathrm{F}, 1200^{\circ} \mathrm{F}$, and $1000^{\circ} \mathrm{F}$ ). All tests on Day 4 were performed with rapid 
heating and cooling rates. Finally, the series of tests performed on Day 5 consisted of one non-uniform diagonal spatial heating test, and five non-uniform top-to-bottom spatial heating tests $\left(2000^{\circ} \mathrm{F}\right)$. All tests on Day 5 were performed with rapid heating and cooling rates.

A long-wave infrared (LWIR) imager with an un-cooled micro-bolometer focal-plane-array, shown in Fig. 32, was located just below and to the left (east) of the tile array test panel as shown in Fig. 33. The view of the tile array test panel from the LWIR imager location is shown in Fig. 34. The LWIR imager was used in conjunction with the Type-R thermocouples to measure the tile array test panel surface temperatures and gradients for comparison to the IR assets' radiometric data. Data from the LWIR imager and the Type-R thermocouples were recorded at $1 \mathrm{~Hz}$ and $5 \mathrm{~Hz}$, respectively, for this series of tests.

Additional tests were performed by the land-based IR assets in-between the tests on the tile array test panel at each land-based staging site to attain point spread functions and to perform standard field calibrations for the IR assets. The point spread functions for this series of tests were attained by focusing on the reflection of the sun from a semi-spherical 2 inch diameter chrome trailer hitch as shown in Fig. 35. The standard field calibrations for this series of tests were attained using two radiometric calibrated blackbody sources, a 1 inch diameter aperture high temperature blackbody with a maximum temperature of $1300^{\circ} \mathrm{F}\left(700^{\circ} \mathrm{C}\right)$ and a 3 inch diameter aperture medium temperature blackbody with a maximum temperature of $800^{\circ} \mathrm{F}\left(425^{\circ} \mathrm{C}\right)$ shown in Fig. 36. These blackbodies were operated as temperature reference sources at various temperatures. Along with these additional tests, meteorological data was collected for atmospheric attenuation of the infrared radiation to be used for radiometric analysis of data. The meteorological data consisted of temperature, pressure, dew-point temperature, and aerosol concentration at the Kirtland Air Force Base (KAFB) weather station which was in close vicinity to the NSTTF and at roughly the same altitude as the top of the Solar Tower.

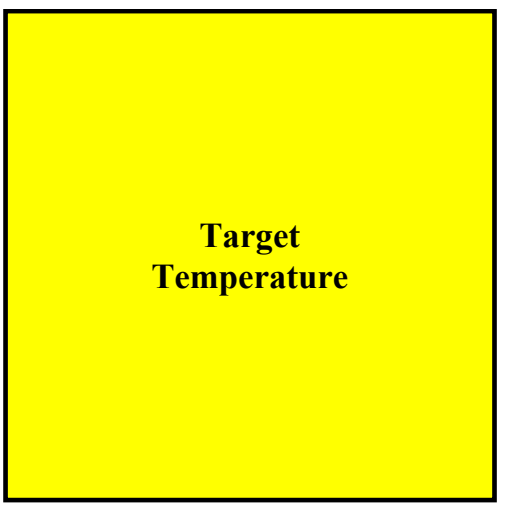

Figure 28. Uniform spatial heating

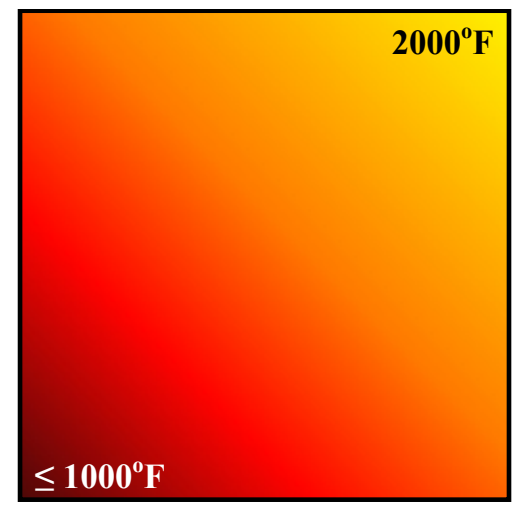

Figure 29. Non-uniform diagonal spatial heating

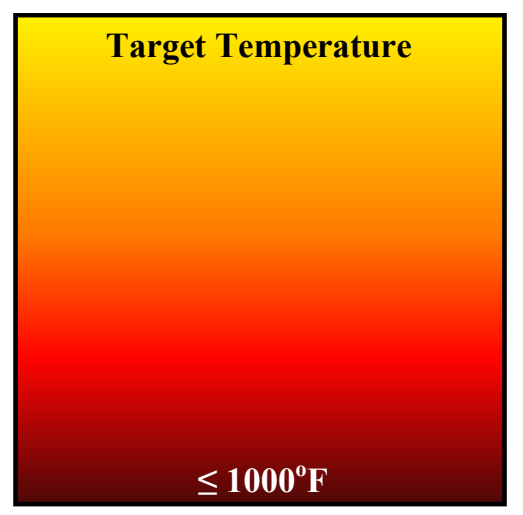

Figure 30. Non-uniform top-tobottom spatial heating

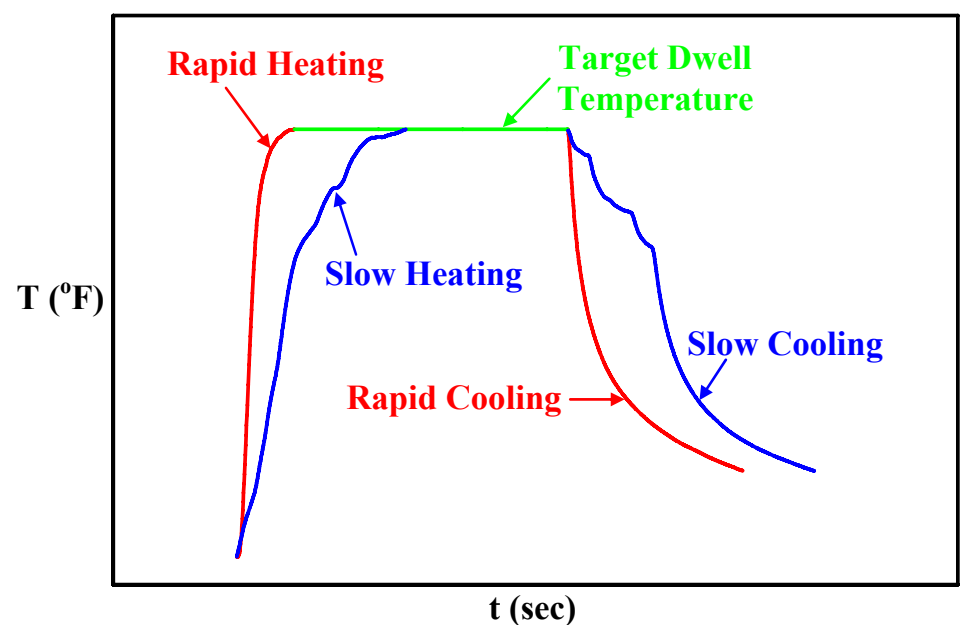

Figure 31. Temperature profiles for various heating and cooling rates 
Table 1. Test matrix

\begin{tabular}{|c|c|c|c|c|}
\hline Day & Site & Spatial Heating & Target Temperature $\left.\mathbf{~}^{\mathbf{0}} \mathbf{F}\right)$ & Participants \\
\hline 1 & 1 & Uniform & $2000,1500,1000$ & MARS \\
\hline & $(\mathrm{RVR})$ & Non-Uniform Diagonal & $2000-\leq 1000$ & WAVE \\
\hline & & & & MARS, WAVE \\
\hline 2 & 1 & Non-uniform Top-to-bottom & $2000,1900,1700,1600$ & MATRIS \\
\hline & $($ RVR) & Non-uniform Top-to-bottom & $1200,1000,800,600$ & MARS, WAVE \\
\hline & & Uniform & 2000 & MATRIS \\
\hline 3 & 2 & Non-uniform Diagonal & $2000-\leq 1000$ & Cast Glance \\
\hline & (EMAF) & Non-uniform Top-to-bottom & $2000,1800,1700$ & MARS \\
\hline & (Airborne) & Uniform & 2000 & \\
\hline & & Non-uniform Diagonal & $2000-\leq 1000$ & Cast Glance \\
\hline 4 & 3 & Non-uniform Top-to-bottom & $2000,1600,1200,1000$ & \\
\hline & (NSTTF) & & $2000-\leq 1000$ & 2000 \\
\hline & & Non-uniform Diagonal & & \\
\hline & & Non-uniform Top-to-bottom &
\end{tabular}

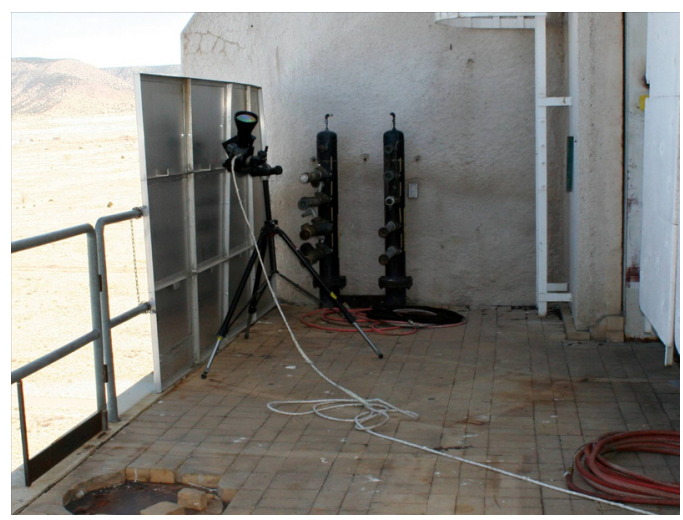

Figure 32. LWIR imager

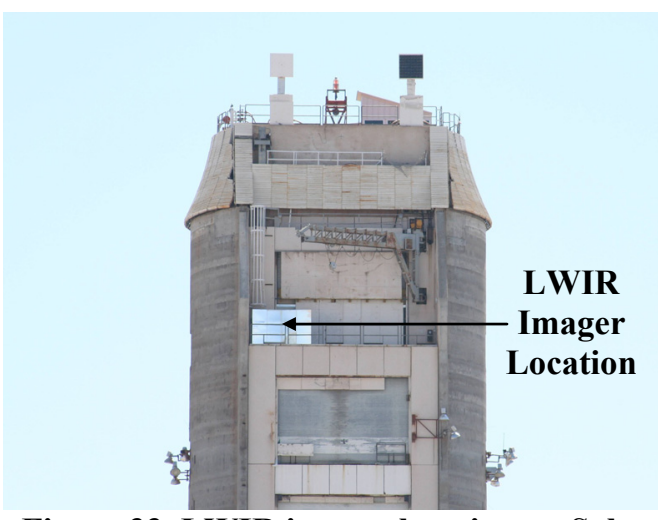

Figure 33. LWIR imager location on Solar Tower

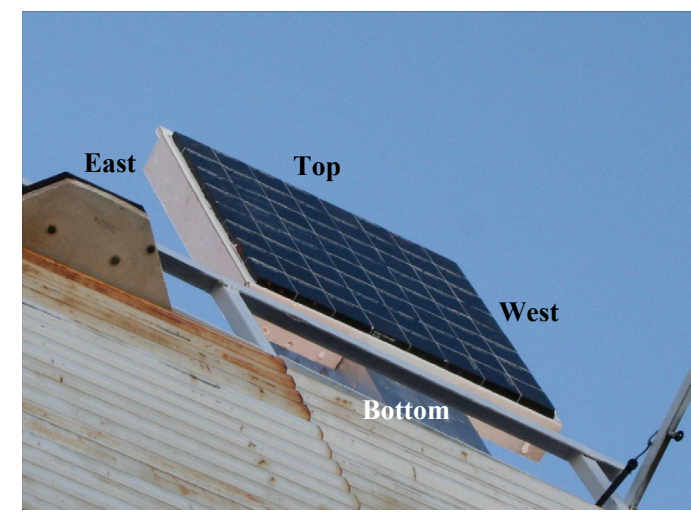

Figure 34. View of the tile array test panel from the LWIR imager location 


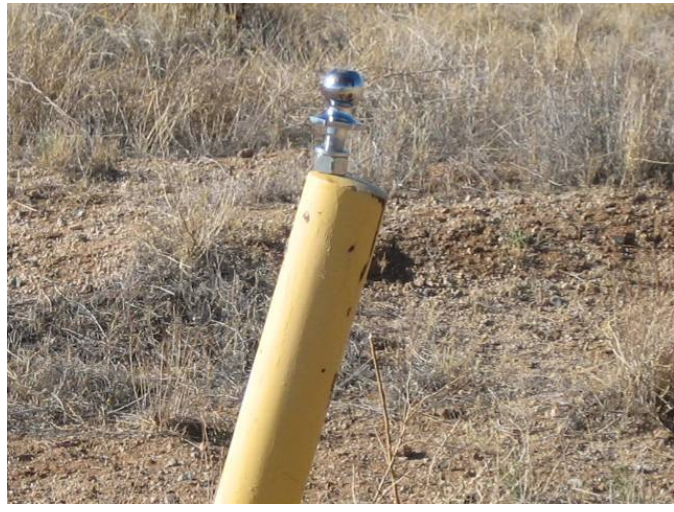

Figure 35. Two inch diameter chrome trailer hitch for point spread functions

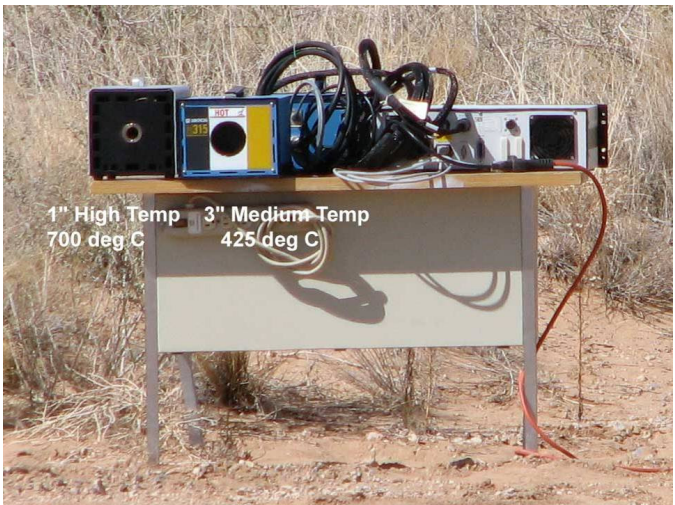

Figure 36. One and three inch aperture blackbodies for standard field calibrations

\section{B. Test Calibration}

Several calibration tests were conducted prior to the arrival of the IR assets to develop a correlation between applied solar heat flux and the resulting surface temperatures on the tile array test panel. First, a target solar flux level was chosen and used to select the groups of four heliostats that would generate this target flux based on the locations of the heliostats in the field and their resulting solar beam sizes. Heliostats closer to the Solar Tower have a beam size that is small in diameter which produces a "hotter" beam, and heliostats farther from the Solar Tower have a beam size that is large in diameter which produces a "cooler" beam. Combinations of close and far heliostats were used to generate the target solar flux level. Next, the selected heliostat groups were aimed at a four foot by four foot white insulation panel mounted on the calibration, or east, NSTTF test stand which had a Kendall Radiometer at its center. A beam characterization system (BCS) imager was used to assess the positioning and uniformity/non-uniformity of the solar beams on the white insulation panel while the Kendall Radiometer was used to verify the target solar flux level. The solar beams were then moved to the tile array test panel where the subsequent temperature attained was recorded. Preliminary calculations determined that a solar flux of $30 \mathrm{~W} / \mathrm{cm}^{2}$ would provide a test panel surface temperature of $2000^{\circ} \mathrm{F}$. Based on this, solar flux levels of 5, 10, 15, 20, 25, and $30 \mathrm{~W} / \mathrm{cm}^{2}$ were chosen for calibration and the resulting temperatures were recorded. Because these exact solar flux levels were not easily achieved, solar flux levels close to these values were accepted. Table 2 provides the target solar flux level, the achieved solar flux level, the average maximum tile array test panel surface temperature as measured by Type-R thermocouples and the LWIR imager, the standard deviation for these surface temperatures, and the number of heliostats used to generate the achieved solar flux level. Type-R temperatures from the numbers $4,5,7$, and 9 instrumented tiles were used for this correlation because they were in the center of the test panel and close to the four solar beam aim-points for the uniform spatial heating test condition. The LWIR imager temperatures reported in the table were obtained using a constant emittance value of 0.65 , based on an approximate 55 degree angle of incidence from the test panel to the LWIR imager from published data on directional emittance of RCG coated tiles ${ }^{20}$, for a small area on the surface of each of the numbers $4,5,7$, and 9 instrumented tiles. The time duration for obtaining the maximum test panel surface temperatures varied between 30 and 60 seconds depending on the solar flux levels. An iterative process then ensued where the groups of heliostats, the solar flux levels, and the spatial aim-points of the heliostats were adjusted to meet the test conditions described in the previous subsection.

Table 2. Solar flux level versus tile array test panel surface temperature correlations

\begin{tabular}{|c|c|c|c|c|c|c|}
\hline $\begin{array}{c}\text { Target Solar } \\
\text { Flux Level } \\
\left(\mathrm{W} / \mathrm{cm}^{2}\right)\end{array}$ & $\begin{array}{c}\text { Achieved Solar } \\
\text { Flux Level } \\
\left(\mathrm{W} / \mathrm{cm}^{2}\right)\end{array}$ & $\begin{array}{c}\text { Avg. Type-R } \\
\text { Temperature } \\
\left({ }^{\circ} \mathrm{F}\right)\end{array}$ & $\begin{array}{c}\text { Standard } \\
\text { Deviation } \\
\left({ }^{\circ} \mathrm{F}\right)\end{array}$ & $\begin{array}{c}\text { Avg. LWIR } \\
\text { Temperature } \\
\left({ }^{\circ} \mathrm{F}\right)\end{array}$ & $\begin{array}{c}\text { Standard } \\
\text { Deviation } \\
\left({ }^{\circ} \mathrm{F}\right)\end{array}$ & $\begin{array}{c}\text { Number of } \\
\text { Heliostats } \\
\text { Used }(\#)\end{array}$ \\
\hline 5 & 4.4 & 934 & 40 & 937 & 33 & 4 \\
\hline 10 & 11.7 & 1349 & 58 & 1343 & 55 & 12 \\
\hline 15 & 17.4 & 1593 & 29 & 1581 & 33 & 20 \\
\hline 20 & 19.6 & 1712 & 33 & 1705 & 37 & 24 \\
\hline 25 & 23.4 & 1814 & 34 & 1796 & 39 & 32 \\
\hline 30 & 27.6 & 1931 & 32 & 1936 & 32 & 40 \\
\hline
\end{tabular}




\section{Test Results}

\section{A. Uniform Spatial Heating}

An image from the LWIR imager taken a few seconds before the removal of the solar beams for the uniform spatial heating test condition with a target temperature of $2000^{\circ} \mathrm{F}$ is shown in Fig. 37. The location of each of the numbered instrumented LI 900 tiles and subsequent approximate areas for the temperature measurements from the LWIR imager are also shown in Fig. 37. Image mapping was not performed on the LWIR image shown in Fig. 37, thus it has the same orientation as the images acquired during this series of tests. However, image mapping will be used on the LWIR images for comparison to the IR assets' radiometric data. A visible image of the tile array test panel illuminated by the solar beams for this same test condition is shown in Fig. 38. The fairly uniform color across the test panel in the LWIR image indicates a uniform spatial heating and temperature arrangement for this test condition. Note that the alumina paper insulation in-between the tiles shows up brighter or higher in temperature as a result of having a different emissivity than the tiles. Also, the instrumented LI 900 tiles on the test panel appear to be slightly brighter in color or higher in temperature than the un-instrumented tiles surrounding them in Figs. 37 and 38. This is most likely due again to a slight difference in emissivity between them, because the instrumented LI 900 tiles were made a few months before this series of tests in a batch separate from the un-instrumented LI 900 tiles which were reclaimed from Return-to-Flight (RTF) test articles that were made several years before this series of tests. The brighter and darker colored strips at the bottom and to the east of the test panel in Fig. 37 are the sides of the LI 900 tiles and the high temperature side insulation boards as shown in Fig. 34. The sides of the LI 900 tiles on the bottom portion of the test panel are brighter because they were horizontal to the ground when the test stand was in its vertical testing position as shown in Fig. 25, and therefore were at an angle closer to normal with respect to the LWIR imager creating a more direct exposure path to the imager.

A plot of the temperatures measured by the Type-R thermocouples for this test condition is shown in Fig. 39. Also shown in the plot are the solar flux levels as measured by the Kendall Radiometers at the center of the calibration, or east, test stand and below and partially shielded by the tile array test panel on the primary, or west, test stand. The solar flux level indicated by the east Kendall in Fig. 39 represents the target solar flux level for this test condition, while the solar flux level indicated by the west Kendall in Fig. 39 is purely a reference for when the solar beams illuminated the test panel and provides an estimate of variation in solar insolation, or incident solar radiation, during the test. Fluctuations in the solar insolation can result from cloud cover or particulates and aerosols in the air. The temperature profiles for the Type-R thermocouples in Fig. 39 are mostly positioned in a band between $1700^{\circ} \mathrm{F}$ and $2100^{\circ} \mathrm{F}$, quantifying the near uniform temperatures of this test condition. A plot of a few of the temperatures measured by both the Type-R thermocouples and the LWIR imager for instrumented tile numbers 2, 3, and 7 which span the temperature band is shown in Fig. 40. The agreement between these three LWIR and Type-R temperature measurements for this test condition was fair with a root mean square (rms) difference of $104.7^{\circ} \mathrm{F}$. Finally, as indicated by the abrupt temperature and solar flux level rates in Fig. 39, the test panel experienced rapid heating, a two minute dwell at the target temperature, and rapid cooling.

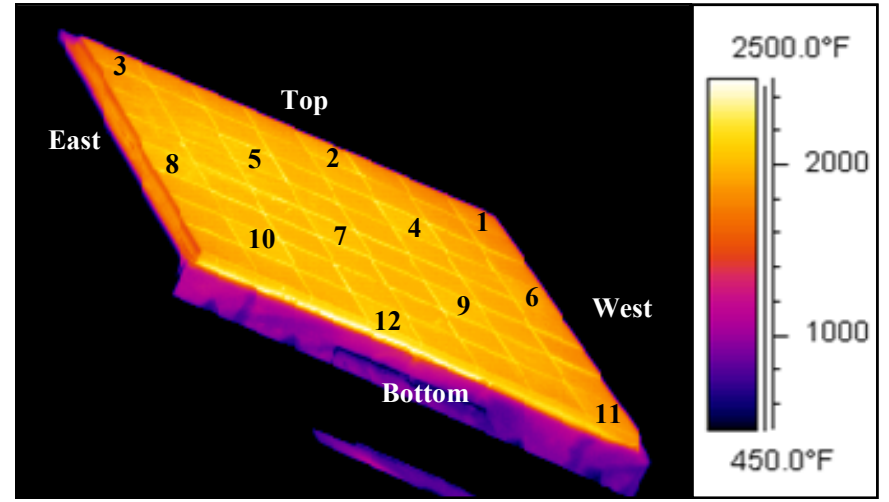

Figure 37. LWIR image of uniform spatial heating test condition

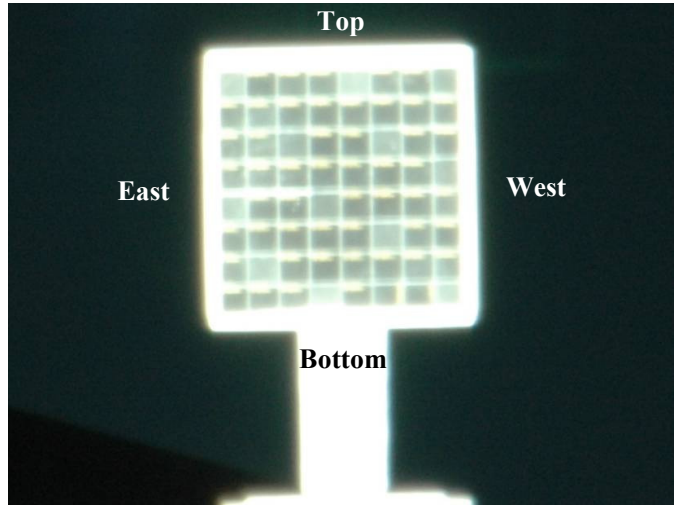

Figure 38. Visible image of uniform spatial heating test condition 


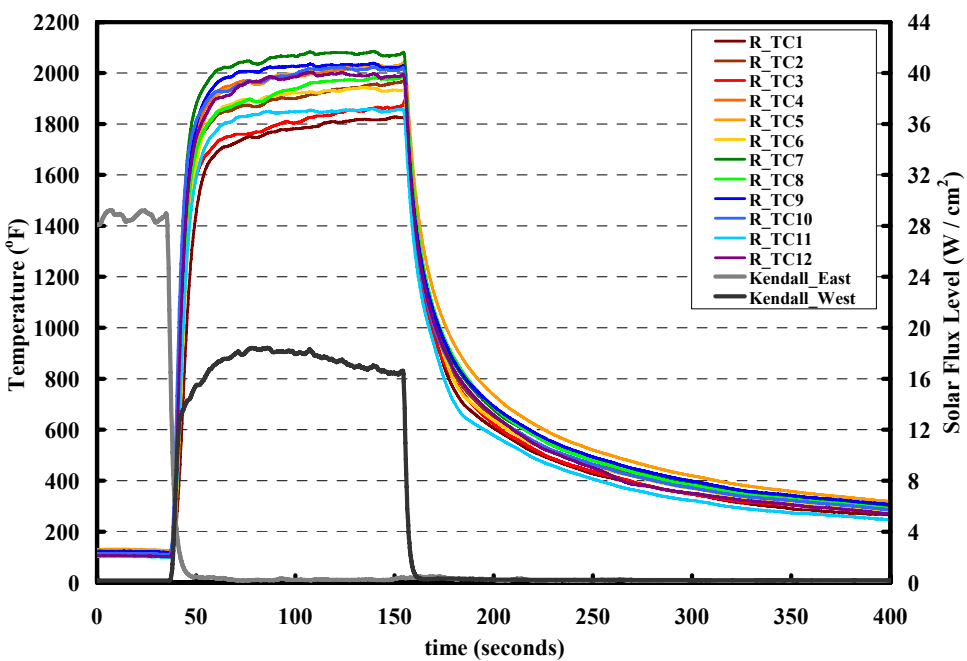

Figure 39. Type-R temperature results with solar flux levels for the uniform spatial heating test condition

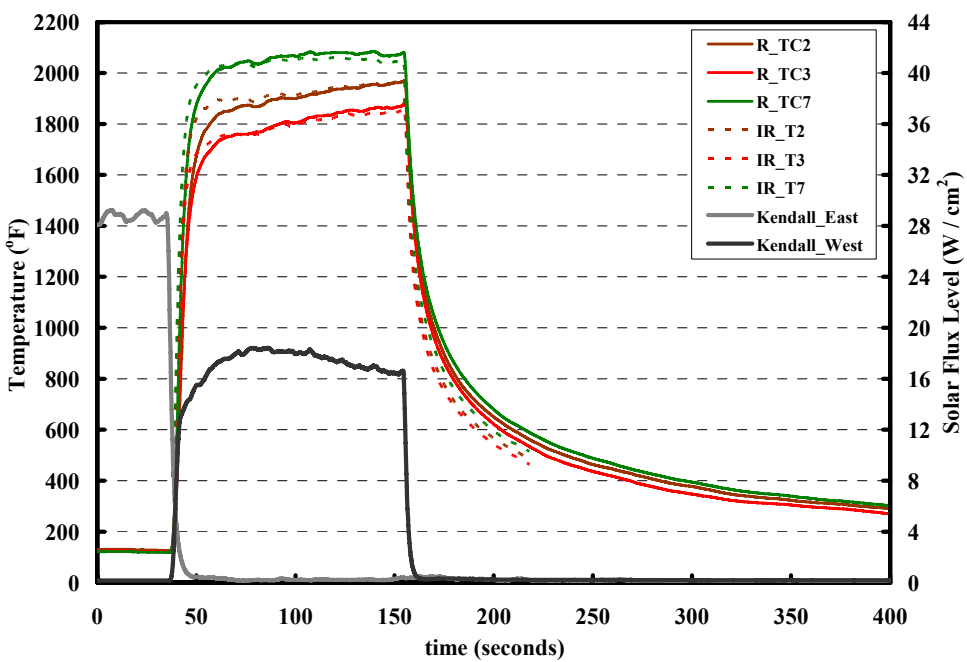

Figure 40. A few Type-R and LWIR temperature results with solar flux levels for the uniform spatial heating test condition

\section{B. Non-uniform Diagonal Spatial Heating}

An image from the LWIR imager taken a few seconds before the removal of the solar beams for the nonuniform diagonal spatial heating test condition with a target temperature of approximately $2000^{\circ} \mathrm{F}$ in the top west corner and less than or equal to $1000^{\circ} \mathrm{F}$ in the bottom east corner of the tile array test panel is shown in Fig. 41. A visible image for this same test condition is shown in Fig. 42. The fairly non-uniform "point source" profile of the bright color in the top west corner through to the "rainbow" of darker color on the east and bottom edges of the test panel in the LWIR image indicates a two-dimensional non-uniform diagonal heating and temperature gradient for this test condition. Again, the alumina paper insulation and the instrumented LI 900 tiles appear to be slightly brighter in color or higher in temperature than the un-instrumented tiles surrounding them in Figs. 41 and 42 . The sides of the LI 900 tiles and the high temperature side insulation boards do not show up at all in Fig. 41 indicating significantly less heating of these areas by solar beam illumination when compared to Fig. 37.

A plot of the temperatures measured by the Type-R thermocouples and solar flux levels measured by the Kendal Radiometers for this test condition is shown in Fig. 43. The first half of the solar flux levels indicated by the 
east Kendall in Fig. 43 represents the target solar flux level for this test condition and the second half represents the solar flux level at the center of the temperature gradient on the tile array test panel due to a shift in the spatial aimpoints to the top west corner of the calibration panel during solar flux verification. The temperature profiles for the Type-R thermocouples in Fig. 43 are positioned in a fairly non-uniform "point source" and "rainbow" profile with temperatures between $600^{\circ} \mathrm{F}$ and $2000^{\circ} \mathrm{F}$, quantifying the two-dimensional non-uniform diagonal temperature gradient for this test condition. Note the grouping of temperature profiles from the instrumented tiles in a diagonal fashion in Fig. 43; number 1 by itself, numbers 2, 4, and 6 agree fairly closely, numbers 5, 7, and 9 agree almost perfectly, numbers 3 and 11 in the corners agree almost perfectly, numbers 8 and 10 agree very closely, and number 12 while it should agree with 8 and 10 has a slightly higher temperature which could be a result of its position at the bottom of the test panel and at an angle conducive to more illumination by the solar beams then numbers 8 and 10 for this test condition. These groupings suggest an almost perfect two-dimensional spatial heating and temperature gradient with the slight deviation of instrumented tile number 12. A plot of a few of the temperatures measured by both the Type-R thermocouples and the LWIR imager for instrumented tile numbers 1, 4, 7, and 10 which span the temperature "point source" and "rainbow" profile is shown in Fig. 44. The agreement between these four LWIR and Type-R temperature measurements for this test condition was great with an rms difference of $70.0^{\circ} \mathrm{F}$. Finally, the test panel experienced rapid heating, a two minute dwell at the target temperature, and rapid cooling.

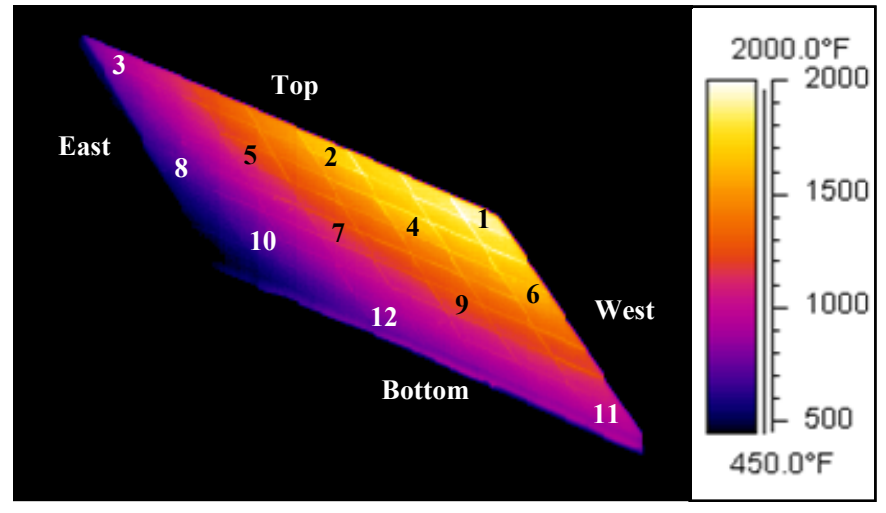

Figure 41. LWIR image of non-uniform diagonal spatial heating test condition

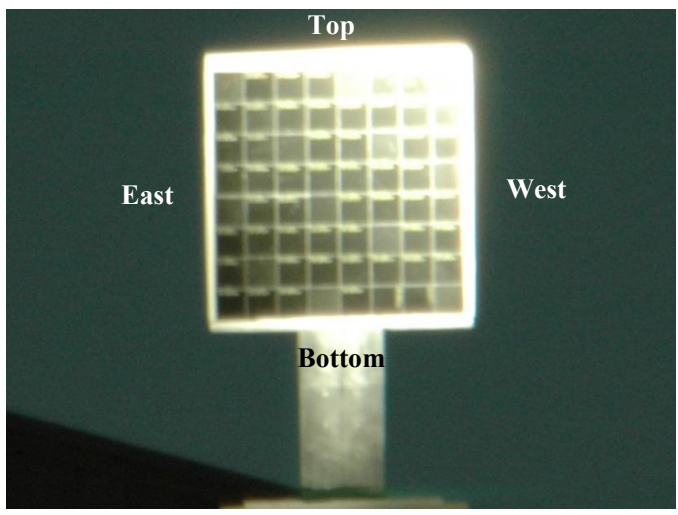

Figure 42. Visible image of non-uniform diagonal spatial heating test condition

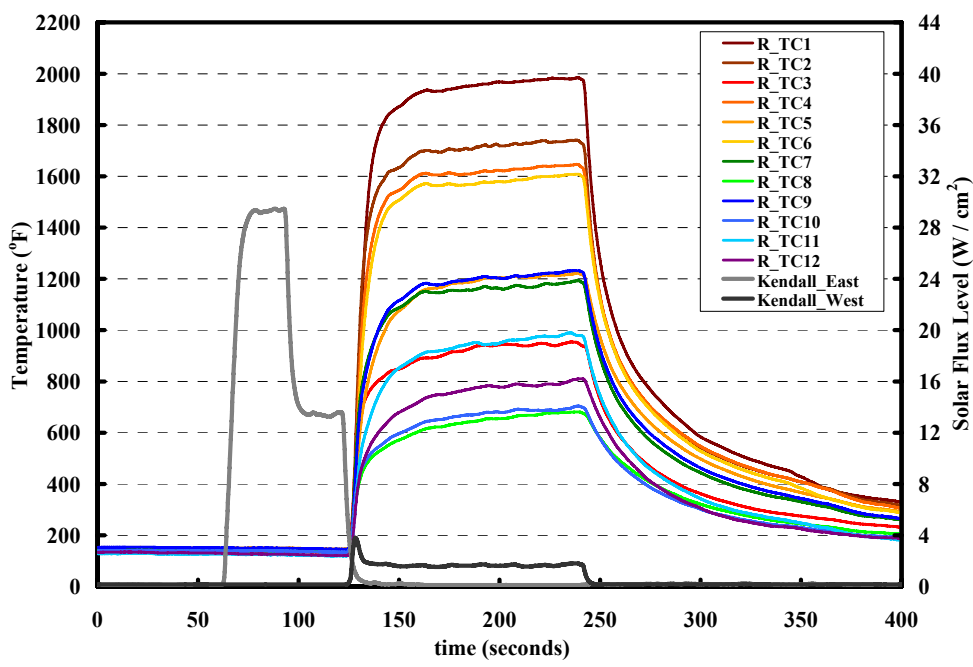

Figure 43. Type-R temperature results with solar flux levels for the non-uniform diagonal spatial heating test condition 


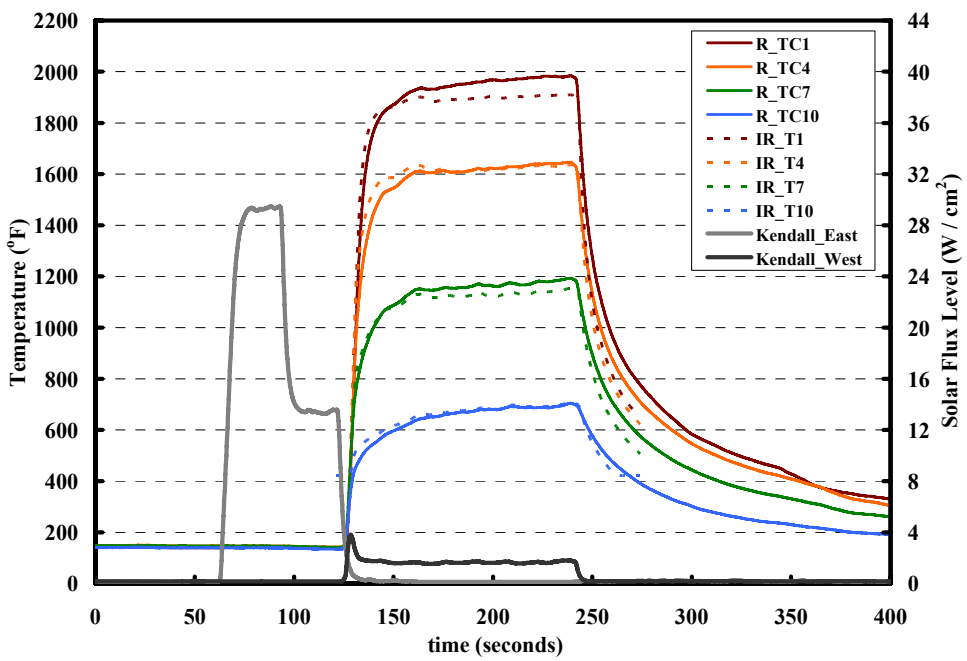

Figure 44. Type-R and LWIR temperature results with solar flux levels for the non-uniform diagonal spatial heating test condition

\section{Non-uniform Top-to-bottom Spatial Heating}

An image from the LWIR imager taken a few seconds before the removal of the solar beams for the nonuniform top-to-bottom spatial heating test condition with a target temperature of approximately $2000^{\circ} \mathrm{F}$ at the top of the tile array test panel is shown in Fig. 45. A visible image for this same test condition is shown in Fig. 46. The fairly non-uniform "ladder" profile of the bright color across the top through to the darker color across the bottom of the test panel in Fig. 45 indicates a one-dimensional non-uniform top to bottom heating and temperature gradient for this test condition. Again, the alumina paper insulation and the instrumented LI 900 tiles on the test panel appear slightly brighter in color in Figs. 45 and 46. The sides of the LI 900 tiles and the high temperature side insulation boards are less illuminated by the solar beams in Fig. 45 when compared to Fig. 37, with only the sides of the tiles and side insulation board in the top east side of the test panel appearing in the image. Again, this effect and the reduced reflectance of the solar beams from the test stand when comparing Figs. 38 and 46 were the main reasons for switching to this test condition from the uniform spatial heating test condition.

A plot of the temperatures measured by the Type-R thermocouples and the solar flux levels measured by the Kendall radiometers for this test condition is shown in Fig. 47. The solar flux level indicated by the east Kendall in Fig. 47 represents the solar flux level at the center of the temperature gradient on the tile array test panel due to the spatial aim-points used during this test on the calibration panel. The temperature profiles for the Type- $R$ thermocouples in Fig. 47 are positioned in a fairly non-uniform "ladder" profile with temperatures between $500^{\circ} \mathrm{F}$ and $2100^{\circ} \mathrm{F}$, quantifying the one-dimensional non-uniform top-to-bottom temperature gradient for this test condition. Note the grouping of temperature profiles from the instrumented tiles that are in the same row from top to bottom in Fig. 47; numbers 1, 2, and 3 in row one agree fairly closely, numbers 4 and 5 in row two agree almost perfectly, number 6 in row three by itself, numbers 7 and 8 in row four don't agree very closely, however numbers 8 and 9 agree fairly closely even though they are in separate rows, and numbers 10,11 , and 12 agree fairly closely even though they are also in separate rows. These groupings suggest a slight deviation from a perfect one-dimensional non-uniform top-to-bottom spatial heating and temperature gradient, but remain within acceptable limits. A plot of a few of the temperatures measured by both the Type-R thermocouples and the LWIR imager for instrumented tile numbers 2, 4, 7, 9, and 12 which span the temperature "ladder" profile is shown in Fig. 48. The agreement between these five LWIR and Type-R temperature measurements for this test condition was great with an rms difference of $74.6^{\circ} \mathrm{F}$. Finally, the test profile for this test condition consisted of rapid heating, a two minute dwell at the target temperature, and rapid cooling. 


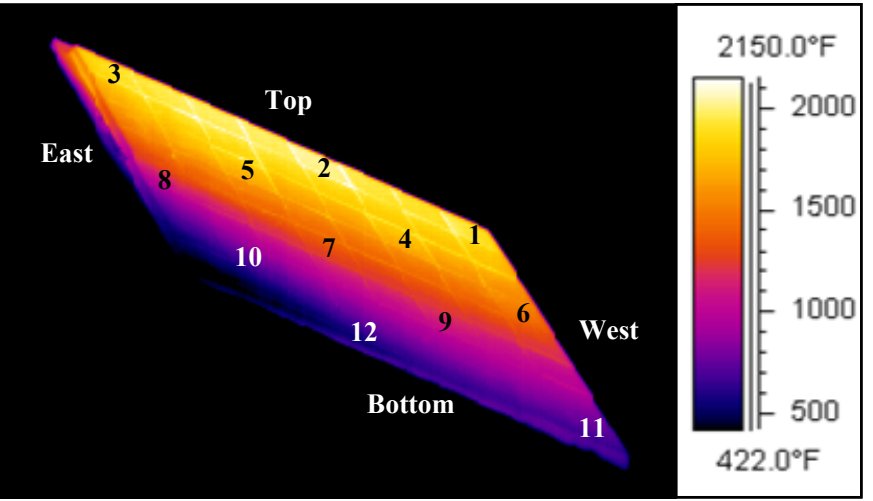

Figure 45. LWIR image of non-uniform top-to-bottom spatial heating test condition

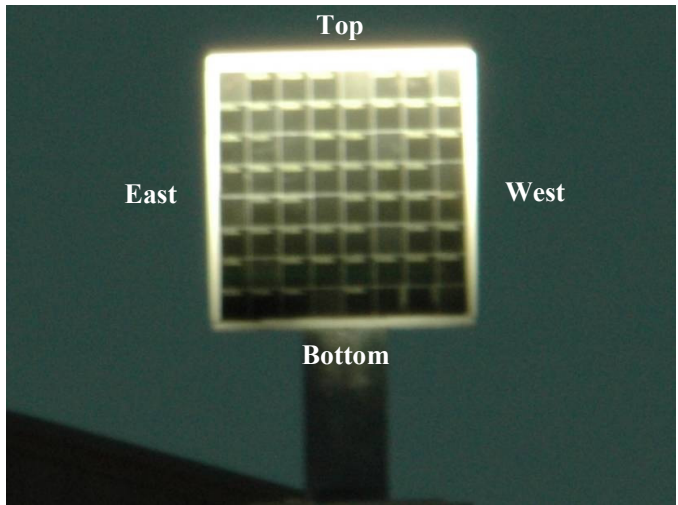

Figure 46. Visible image of non-uniform top-to-bottom spatial heating test condition

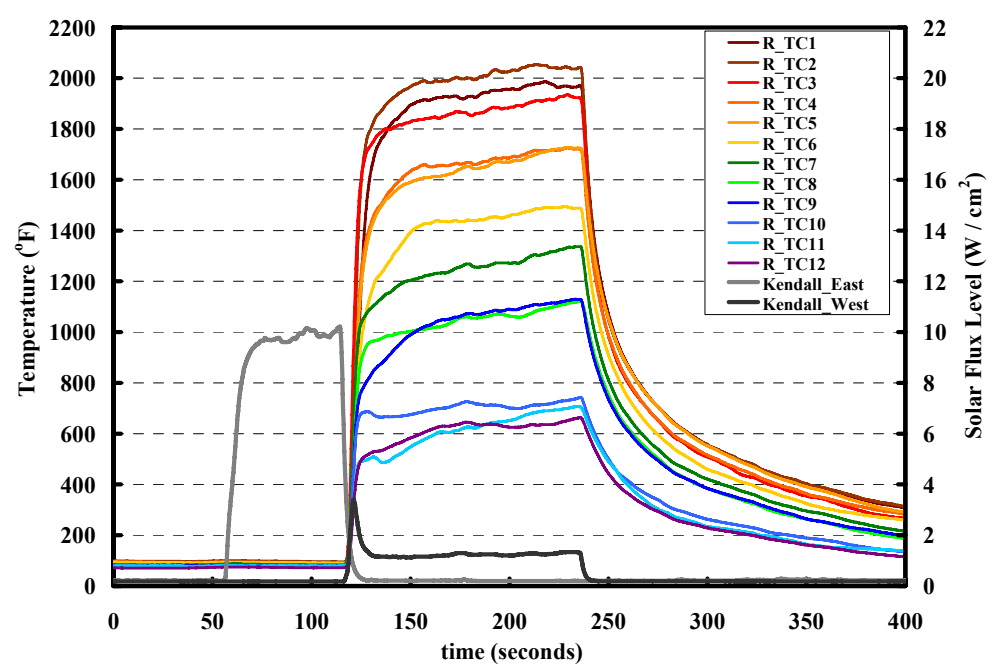

Figure 47. Type-R temperature results with solar flux levels for the non-uniform top-to-bottom spatial heating test condition

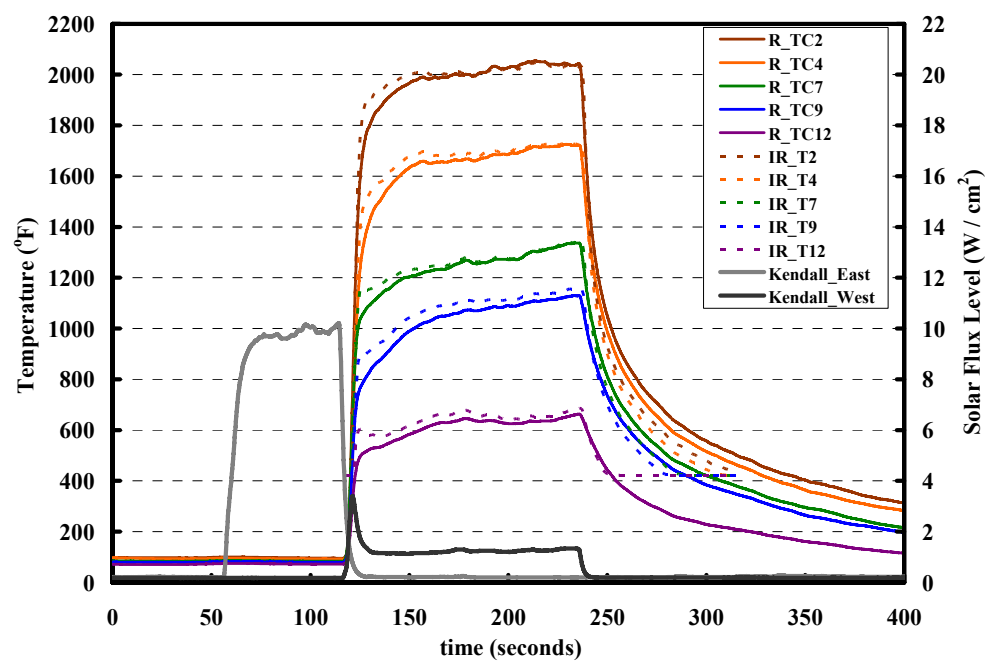

Figure 48. Type-R and LWIR temperature results with solar flux levels for the non-uniform top-to-bottom spatial heating test condition 


\section{Infrared Imaging Assets Results}

Five unprocessed SWIR images of the tile array test panel taken with the MARS system for each of the three spatial heating test conditions and from each of the three land-based IR imaging assets' staging sites are presented in Figs. 49 through 53. Figures 49 through 51 represent each of the three spatial heating test conditions as imaged from Site 3 (NSTTF), with the uniform spatial heating test condition shown in Fig. 49, the non-uniform diagonal spatial heating test condition shown in Fig. 50, and the non-uniform top-to-bottom spatial heating test condition shown in Fig. 51. Each of the test conditions shown in Figs. 49 through 51 had a target temperature of $2000^{\circ} \mathrm{F}$ and a minimum temperature equal to $1000^{\circ} \mathrm{F}$ or lower for the non-uniform spatial heating test conditions. Figures 52 and 53 represent the non-uniform top-to-bottom spatial heating test condition as imaged from Site 2 (EMAF) and Site 1 (RVR), respectively. An unprocessed NIR image of the tile array test panel taken with the WAVE optical bench system for the non-uniform top-to-bottom spatial heating test condition from Site 2 (EMAF) is shown in Fig. 54.

A preliminary irradiance versus mean counts per pixel plot associated with the WAVE optical bench system for a uniform spatial heating test condition is shown in Fig. 55. The red line is calculated total (thermal + reflected solar) irradiance at the sensor, and the blue line is calculated thermal irradiance at the sensor. The bottom line pair shows data during the 15 seconds after the heliostats begin to heat the test panel, while the top line pair shows data during 20 seconds after the heliostats came off the test panel during cool down. The difference between the total irradiance and thermal only lines during the heat up phase is due to heliostat solar energy reflected from the test panel. The useful portion of the data in Fig. 55 for the calibration of counts versus thermal irradiance is provided by the cool down and latter part of the heat up cycle because all of the irradiance at these segments is due to thermal irradiance without solar beam reflection. A preliminary calibration also associated with the WAVE system and this same test condition is shown in Fig. 56. The detector response is well characterized by a second degree polynomial with a correlation coefficient of 0.996. At this point in the analysis, the data shown in Figs. 55 and 56 are uncorrected for a variety of known effects including radiant behavior of the tile-to-tile gap filler material and the aperture restriction applied to the sensor of approximately $88 \%$ (aperture restriction was applied to this particular sensor during the test to mitigate saturation). Analyses of this radiometric data and all other radiometric data taken during this series of tests at the Solar Tower for each of the IR imaging assets were still being performed at the time of submission for this paper.

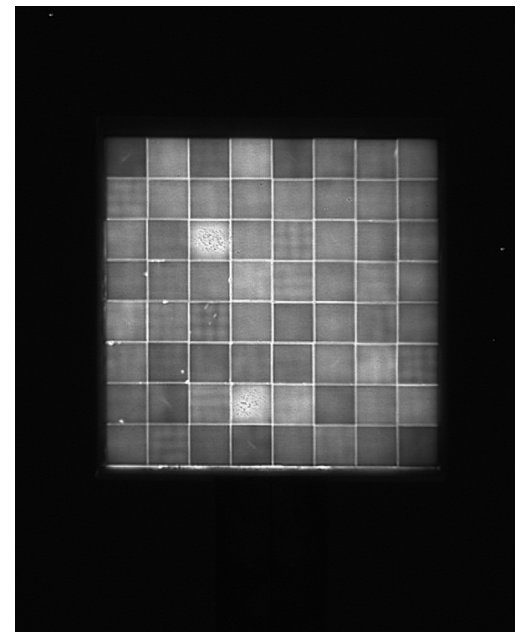

Figure 49. Uniform spatial heating (SWIR, MARS, Site 3)

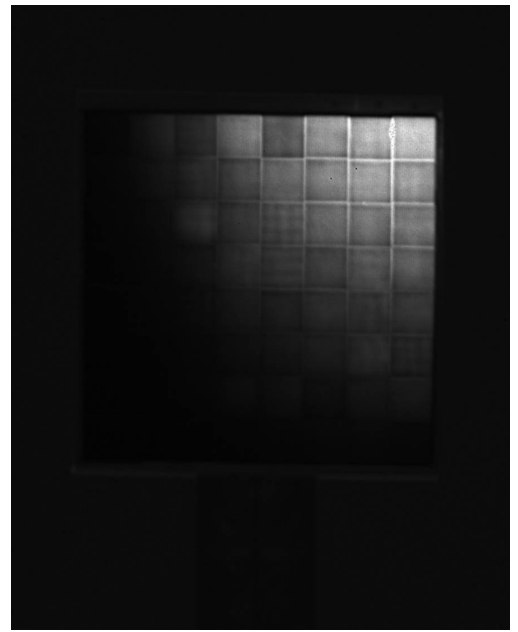

Figure 50. Non-uniform diagonal spatial heating (SWIR, MARS, Site 3)

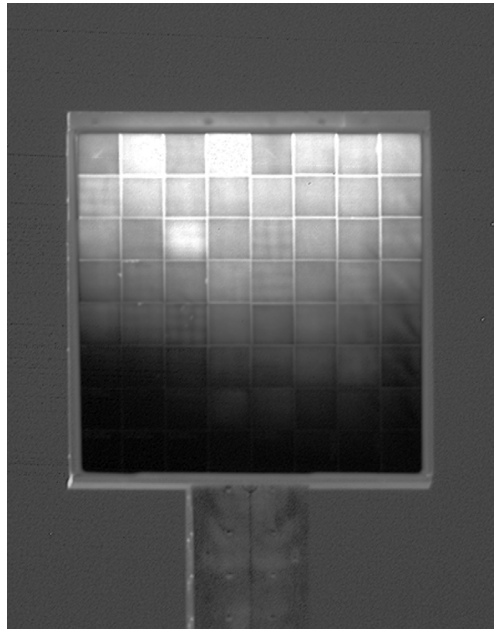

Figure 51. Non-uniform top-to-bottom spatial heating (SWIR, MARS, Site 3) 


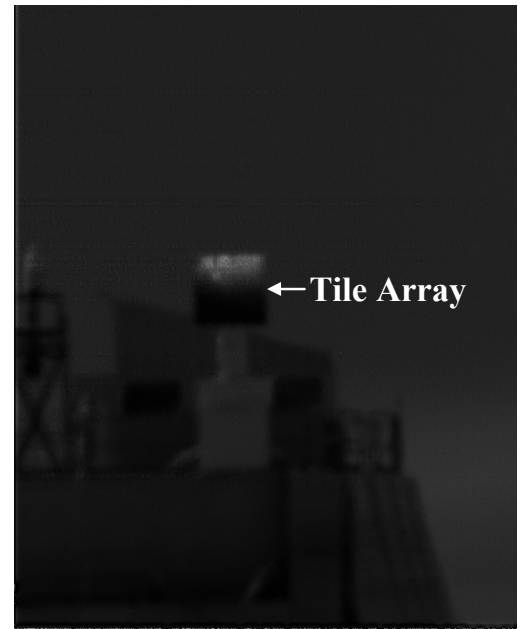

Figure 52. Non-uniform top-to-bottom spatial heating (SWIR, MARS, Site 2)

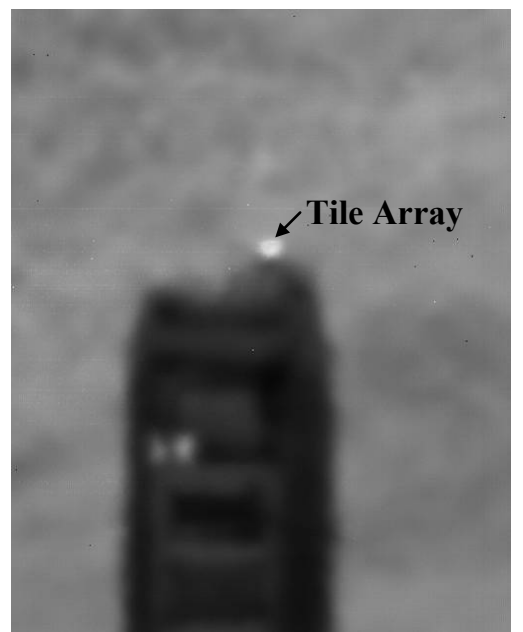

Figure 53. Non-uniform top-to-bottom spatial heating (SWIR, MARS, Site 1)

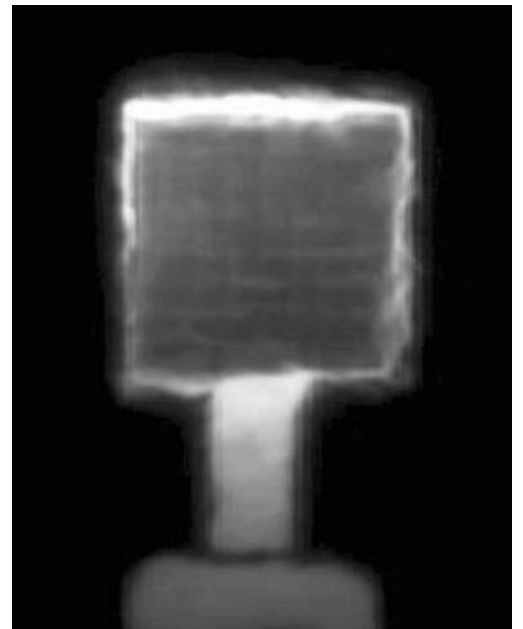

Figure 54. Non-uniform top-to-bottom spatial heating (NIR, WAVE, Site 2)

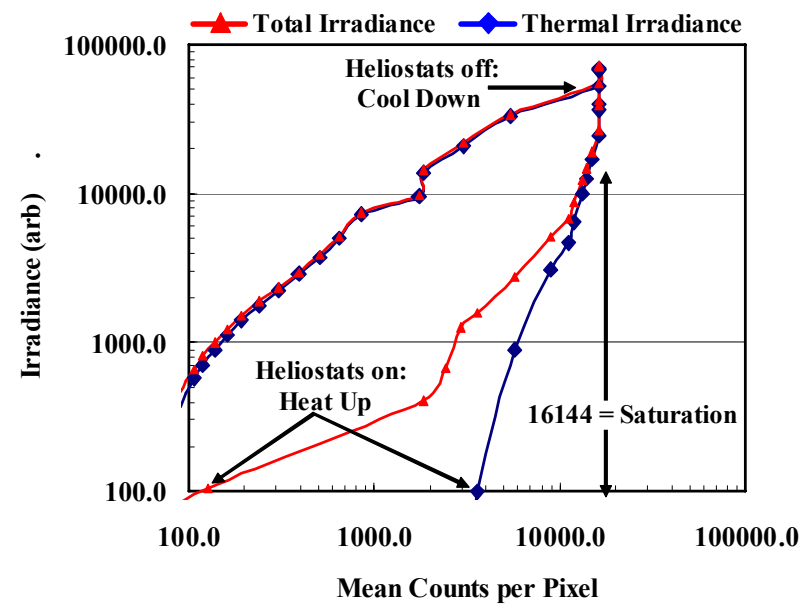

Figure 55. Preliminary irradiance versus mean counts per pixel plot for a uniform spatial heating test

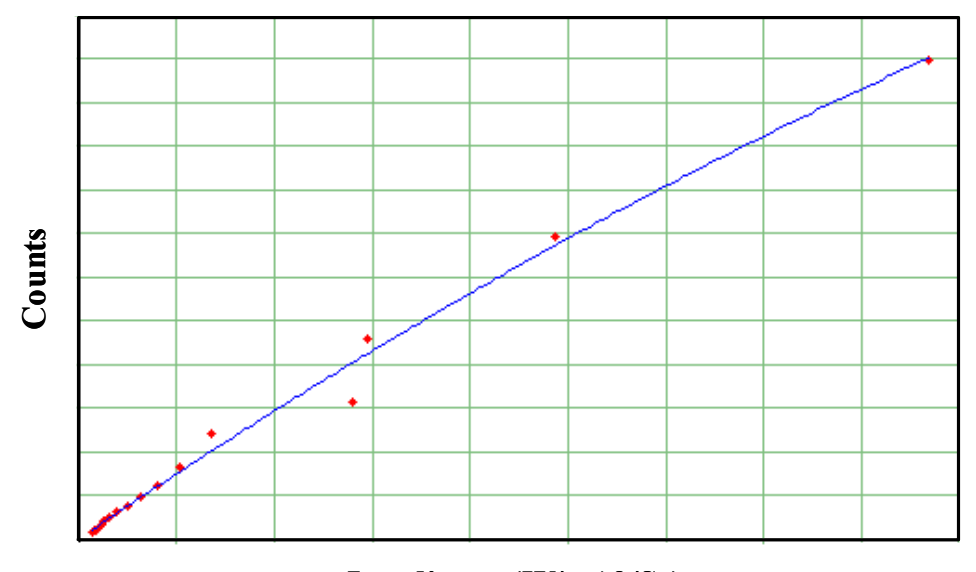

Irradiance $\left(\mathrm{W} / \mathbf{m}^{\wedge} \mathbf{2} / \mathrm{Sr}\right)$

Figure 56. Preliminary calibration curve for a uniform spatial heating test (uncorrected for aperture restriction) 


\section{Concluding Remarks}

An overview of the NASA Engineering and Safety Center (NESC) Hypersonic Thermodynamic Infrared Measurements (HYTHIRM) assessment team's series of tests at the Sandia National Laboratories' National Solar Thermal Test Facility (NSTTF) to perform radiometric calibration and validation of land-based and airborne IR imaging assets and tools for remote thermographic imaging was provided. The IR assets and tools can subsequently be used for thermographic imaging of the Space Shuttle Orbiter during entry aero-heating to provide flight boundary layer transition (BLT) thermography data that could be utilized for calibration and validation of empirical and theoretical aero-heating tools. The NSTTF Solar Tower provided an ideal test bed for this series of radiometric calibration and validation tests because it rapidly heated a 4 foot by 4 foot tile array test panel, which consisted of 64 instrumented and un-instrumented LI 900 ceramic tiles, same as the tiles used on the windward surface of the Orbiter, to spatially uniform and non-uniform elevated temperatures with the solar beams from the heliostats, or mirrored solar collectors. Also, the unsheltered-open-air environment of the Solar Tower was conducive to obtaining unobstructed radiometric data by land-based and airborne IR imaging assets of the Orbiter-like entry temperatures. Three land-based IR imaging assets, MARS, WAVE optical bench, and MATRIS, were staged at three different sites on Sandia National Laboratories property at various distances from the Solar Tower on four consecutive days with an airborne IR asset, Cast Glance, participating on two non-consecutive days for a total of five days of testing. Site 1 was the Robotics Vehicle Range (RVR) at a distance of 5.3 miles from the Solar Tower, Site 2 was the Explosives Machining and Assembly Facility (EMAF) at 1.4 miles from the Solar Tower, and Site 3 was the NSTTF at 0.3 miles from the Solar Tower. The airborne IR asset flew six test support position profiles with proximities of 30,25, 20,15,10, and 5 nautical miles from the Solar Tower. All IR assets were able to successfully image the tile array test panel from these sites using near infrared (NIR), short-wave infrared (SWIR), and mid-wave infrared (MWIR) imagers for three types of test conditions. The three types of test conditions consisted of uniform spatial heating of the test panel to various target temperatures, non-uniform spatial heating of the test panel with a large temperature gradient maintained across the diagonal of the test panel $\left(2000^{\circ} \mathrm{F}\right.$ at one corner and $1000^{\circ} \mathrm{F}$ or lower at the opposite corner), and non-uniform spatial heating of the test panel with a large temperature gradient maintained from top to bottom on the test panel (target temperature across the top and $1000^{\circ} \mathrm{F}$ or lower across the bottom). The non-uniform diagonal spatial heating of the test panel was mainly used to determine the intra-frame dynamic range of the IR assets, and the non-uniform top-to-bottom spatial heating of the test panel was used in place of the uniform spatial heating to minimize reflectance of the solar beams from the test stand supports. A long-wave infrared (LWIR) imager was used in conjunction with the Type-R thermocouple instrumented LI 900 ceramic tiles to measure the tile array test panel surface temperatures and gradients for comparison to the IR assets' radiometric data. Surface temperatures and gradients recorded by the Type-R thermocouples and the LWIR imager were in good agreement with each other, with rms differences of $104.7^{\circ} \mathrm{F}$ for the uniform, $70.0^{\circ} \mathrm{F}$ for the non-uniform diagonal, and $74.6^{\circ} \mathrm{F}$ for the non-uniform top-to-bottom spatial heating test conditions. Several unprocessed SWIR and NIR images for each of the three spatial heating test conditions and from each of the three land-based IR imaging assets' staging sites were presented, and typical results for a preliminary irradiance versus mean counts per pixel comparison and calibration curve for a uniform spatial heating test were provided.

\section{Acknowledgments}

The authors would like to acknowledge and thank the following people for their contribution in making this series of tests a success:

- Scott Berry, Paul Krasa, and Rosemary Baize, HYTHIRM Project Management, NASA Langley Research Center

- Wayne Geouge, Quinton Duncan, Kathleen Devol, Charles Burtnette, Rodney Robertson, William Dale Lupton, E. Thomas Haul Jr., and George Hilton, Tile Array Test Panel Fabrication and Instrumentation Technicians, NASA Langley Research Center

- Frank Lin, Martin Wilson, and Beckey Henn, Instrumented LI 900 Tile Contacts, NASA Johnson Space Center and NASA Kennedy Space Center

- Andrew Mccrea, Test Environment Visualization and Support, ATK Space Division, NASA Langley Research Center 
- Michael Usher, Mario Moreno, John (JJ) Kelton, Daniel Ray, Blaine Emms, Ed Phillips, Kye Chisman, and Ernie Trujillo, National Solar Thermal Test Facility Personnel, Sandia National Laboratories

- Ron Dantowitz and Marek Kozubal, MARS Personnel, Clay Center Observatory Dexter Southfield Schools

- John Collier, Richard Tantaris, and John Wiseman, WAVE Personnel, WB-57F Program NASA Johnson Space Center and Southern Research Institute

- Dan Banks, Kames Stelle, and Tim Montgomery, MATRIS Personnel, NASA Dryden Flight Research Center

- $\quad$ Steve Tack, Cast Glance Personnel, NAVAIR US Navy

- Dan Puetz and Benjamin Moya, Robotics Vehicle Range and Explosives Machining and Assembly Facility Contacts, Sandia National Laboratories

- Marjorie Shoemake, Meteorological Data Contact, Kirtland Air Force Base

- George Boyden, Manager, Sandia Peak Ski and Tramway

\section{References}

${ }^{1}$ Blanchard, R.C., Wilmoth, R.G., Glass, C.E., Merski, N.R., Berry, S.A., Bozung, T.J., Tietjen, A., Wendt, J., and Dawson, D., "Infrared Sensing Aeroheating Flight Experiment: STS-96 Flight Results," Journal of Spacecraft and Rockets, Vol. 38, No.4, 2001, pp.465-472.

${ }^{2}$ Blanchard, R.C., Anderson, B.P., Welch, S.S., Glass, C.E., Berry, S.A., Merski, N.R., Banks, D.W., Tietjen, A., and Lovern, M., "Shuttle Orbiter Fuselage Global Temperature Measurements from Infrared Images at Hypersonic Speeds," AIAA Paper 2002-4702, August, 2002.

${ }^{3}$ Berry, S.A., Merski, N.R., and Blanchard, R.C., "Wind Tunnel Measurements of Shuttle Orbiter Global Heating with Comparison to Flight," AIAA Paper 2002-4701, August, 2002.

${ }^{4}$ Throckmorton, D.A., Zoby, E.V., and Kantsios, A.G., "Shuttle Infrared Leeside Temperature Sensing (SILTS) Experiment," AIAA Paper 85-0328, January, 1985.

${ }^{5}$ Chocol J. C., "Infrared Imagery of Shuttle (IRIS)," Martin Marietta Corporation Final Report, MCR-76-564, Contract NAS2-9381, August, 1977.

6 "Infrared Imagery of Shuttle (IRIS) Experiment," IRIS/STS-3 Engineering Report, NASA-CR-193052, NASA AMES Research Center, June, 1982.

${ }^{7}$ Green, M.J., Budnick, M.P., Yang, L., and Chiasson, M.P., "Supporting Flight Data Analysis for Space Shuttle Orbiter Experiments at NASA Ames Research Center," AIAA Paper 83-1532, June, 1983.

${ }^{8}$ Horvath, T., Berry, S., Alter, S., Blanchard, R., Schwartz, R., Ross, M., and Tack, S., "Shuttle Entry Imaging Using Infrared Thermography," AIAA-2007-4267, June 2007

${ }^{9}$ Campbell, C. H., Garske, M. T., Kinder, J., and Berry, S. A., “Orbiter Entry Boundary Layer Flight Testing,” AIAA-20080635, Jan., 2008

${ }^{10}$ Horvath, T., Berry, S., Splinter, S., Daryabeigi, K., Wood, W., Schwartz, R., and Ross, M., "Assessment and Mission Planning Capability for Quantitative Aerothermodynamic Flight Measurements Using Remote Imaging," AIAA-2008-4022, June 2008.

${ }^{11}$ Schwartz, R., Ross, M., Baize, R., Horvath, T., Berry, S., Krasa, P., “A System Trade Study of Remote Infrared Imaging for Space Shuttle Re-entry," AIAA-2008-4023, June 2008.

${ }^{12}$ Ross, M., Werner, M., Mazuk, S., Blanchard, R., Horvath, T. ., Berry, S. ., Wood, W., and Schwartz, R., "Infrared Imagery of the Space Shuttle at Hypersonic Entry Conditions," AIAA-2008-0636, Jan., 7-10, 2008.

${ }^{13}$ Berry, S., Horvath, T., Schwartz, R., Ross, M., Campbell, C., Anderson, B., "IR Imaging of the Shuttle Boundary Layer Transition Flight Experiment," AIAA-2008-4026, June 2008.

${ }^{14}$ Congdon, W.M., Curry, D.M., and Collins, T.J., "Response Modeling of Lightweight Charring Ablators and Thermal Radiation Testing Results," AIAA Paper 2003-4657, July 2003.

${ }^{15}$ Maxwell, C., and Holmes, J., "Central Receiver Test Facility Experiment Manual," SAND86-14921, UNC-235 (Revised), Reprinted March 1988.

${ }^{16}$ Banks, D.W., Blanchard, R.C., and Miller, G.M., "Mobile Aerial Tracking and Imaging System (MATrIS) for Aeronautical Research," NASA TM-2004-212852, August 2004.

${ }^{17}$ Google Earth ${ }^{\mathrm{TM}}$ Software, Version 4.2.0198.2451, Google Inc., Mountain View, CA, 2007.

${ }^{18}$ Google Maps ${ }^{\mathrm{TM}}$ Software, Google Inc., Mountain View, CA, 2007.

${ }^{19}$ Schwartz, R. J., "ViDI: Virtual Diagnostic Interface Volume I- The Future of Wind Tunnel Testing," Contractor Report, NASA CR-2003-212667, December 2003.

${ }^{20}$ Bouslog, S.A., and Cunnington, G.R., "Emittance Measurements of RCG Coated Shuttle Tiles," AIAA paper 92-0851, January 1992. 